\title{
2 The Jingle-Jangle Fallacy in Adolescent Autonomy in the Family: 3 In Search of an Underlying Structure
}

\author{
4 Stijn Van Petegem - Maarten Vansteenkiste • \\ 5 Wim Beyers
}

Received: 26 July 2012/ Accepted: 22 October 2012

(C) Springer Science+Business Media New York 2012

\section{Introduction}

For decades now, the construct of autonomy has received attention in diverse fields of psychology, including developmental (e.g., Zimmer-Gembeck and Collins 2003), crosscultural (e.g., Kagitçibasi 2005) and personality psychology (Ryan and Deci 2006). Yet, the question of how to define and measure autonomy exactly and whether it yields adjustment benefits is not resolved. One of the main problems concerns the conceptual confusion regarding the construct of autonomy, with theorists defining autonomy in different ways and, as a consequence, drawing different conclusions about the "same" construct. This problem further increases by the fact that prevailing operationalizations of autonomy often fail to match the proposed concept of autonomy. Indeed, although several measures are said to tap into autonomous functioning, they relate sometimes barely or even negatively to each other. Such confusion seems almost as old as the discipline of psychology itself, and is referred to as the "jingle-jangle fallacy" (Marsh 1994), with the jingle fallacy pertaining to the belief that scales with the same name measure the same construct (Thorndike 1904) and the jangle fallacy relating to the assumption that two scales with different names measure different constructs (Kelley 1927).

Two decades ago, Ryan and Lynch (1989) already argued that the construct and measurement of autonomy needs clarification. In spite of this call, it seems that even experts in the field sometimes have a hard time to see the wood for the trees. Therefore, the first aim of the present study was to gain insight in the multitude of meanings of autonomy by examining the structure underlying a broad range of autonomy measures that tap into both healthy as well as dysfunctional types of autonomy. Specifically, based on theorizing and recent empirical research (e.g., Ryan and Deci 2006; Vansteenkiste et al. 2005), we tested 
whether the variation in autonomy measures can be captured by two underlying dimensions, that is, autonomy when defined as independent versus dependent functioning and autonomy when defined as volitional versus pressured functioning. The second goal of the study was to relate these retained dimensions to several indicators of psychosocial functioning, including subjective well-being, problem behavior and attachment to the parents.

\section{Autonomy as Independence}

The first approach defines autonomy as independence or self-reliance, that is, the extent to which one behaves, decides, or thinks without relying on others (Steinberg 2002). The opposite of autonomy then involves dependence or reliance on others. During adolescence, the focus is often on the context of the parent-adolescent relationship, that is, autonomy is seen as independence from the parents as opposed to dependence on the parents. This definition is typically adhered to by influential developmental theorists and researchers (e.g., Darling et al. 2008; Smetana et al. 2004; Steinberg 2002). Because of physical, cognitive and social changes that characterize this life period, adolescents are expected to function increasingly independently (Zimmer-Gembeck and Collins 2003). This normative process would be manifest in several domains of adolescents' functioning, including the behavioral, cognitive and emotional domains (e.g., Steinberg 2002; ZimmerGembeck and Collins 2003). As the cognitive component is conceptually less clear and relatively understudied in the developmental literature (but see e.g., Beckert 2007), we focused on the more well-established components of behavioral and emotional independence.

Independent decision making represents a commonly used indicator and a clearly visible manifestation of behavioral independence (e.g., Smetana et al. 2004). Independent decision making relates to the question who decides about a range of daily issues and activities, like the choice of clothing or whether you do chores at home. Whereas unilateral parental decision making indicates complete dependence, adolescent alone decision making reflects complete independence, and joint decision making moderate independence. Previous research (e.g., Smetana et al. 2004) clearly points to a normative increase with age in independent decision making, particularly for decisions relating to personal issues (Qin et al. 2009; Smetana 2000; Smetana et al. 2004). Another indicator of behavioral independence is functional independence (Hoffman 1984), which is defined as the extent to which adolescents are capable of managing practical and personal affairs without soliciting parental help. In addition to this frequently studied behavioral component, independence is said to have emotional manifestations as well (Hoffman 1984; Steinberg 2002; Zimmer-Gembeck and Collins 2003). Emotional independence refers to adolescents' freedom from excessive needs for approval, closeness and emotional support of the parents. Previous research (e.g., Rice 1992) found emotional independence to increase with age, though most studies sampled university students.

As behavioral and emotional independence are supposed to be manifestations of healthy independent functioning (Zimmer-Gembeck and Collins 2003), one may expect these facets to be associated positively to each other and to relate similarly to external variables. However, there is little research explicitly addressing the interrelations between these different facets. The few studies that tapped into both aspects of independent functioning (e.g., Beyers and Goossens 1999) found only slightly positive relationships. As for the association with psychosocial functioning, previous research is rather equivocal and unclear. For instance, even though independence may be expected to yield beneficial correlates during adolescence, independent decision making has been found to relate mainly to more problem behavior (e.g., Kuhn and Laird 2011; Van Petegem et al. 2012). The adjustment correlates of functional and emotional independence are not straightforward either, with some studies reporting that these variables are associated with more adjusted functioning (e.g., Beyers and Goossens 2003) and others reporting a null or even a negative association (e.g., Garber and Little 2001; Lopez et al. 1988).

To account for the above findings, researchers increasingly advocated studying adolescent autonomy in a differentiated manner, thereby taking a more balanced approach. Specifically, to become a self-sufficient adult, independent behavior is considered only healthy when manifested in a developmentally appropriate manner. For instance, independent decision making over personal issues have been shown to be beneficial for early adolescents, whereas independence over moral and conventional issues should be obtained only by late adolescence (Smetana et al. 2004). Hence, both the age as well as the social domain needs to be considered to understand whether independence is healthy.

Additionally, as is increasingly stressed during the last decades (e.g., Allen et al. 1994; Collins and Repinski 1994; Cooper and Grotevant 2011; Youniss and Smollar 1985), a crucial task for adolescents is to strive towards an optimal balance between increased independence and the maintenance of a positive relationship with parents. This is because, for some adolescents, this striving for independence can come at the expense of relational functioning such that adolescents detach themselves from their parents. Detachment entails feelings of disengagement, rejection and

\begin{tabular}{|l|lll|}
\hline Journal : Large 10964 & Dispatch : 26-10-2012 & Pages : 21 \\
Article No. : 9847 & $\square$ & LE & TYPESET \\
MS Code : JOYO-2968 & $\sim_{\text {CP }}$ & $\checkmark$ DISK \\
\hline
\end{tabular}




\section{Autonomy as Volition} et al. 2006). mistrust towards the parents and has been differentiated from healthy manifestations of independence (Beyers et al. 2003). The associations between detachment and external variables are much more straightforward, as detachment consistently relates negatively to indicators of psychosocial functioning (e.g., Lamborn and Groh 2009). In the present research, we included measures assessing both healthy as well as dysfunctional manifestations of independence to examine whether they tap into one or more underlying dimensions, as well as to investigate how they relate to measures of autonomy when defined as volition.

Within the second perspective on autonomy, that is largely rooted in the framework of Self-Determination Theory (SDT, Ryan and Deci 2000), autonomy is defined as selfendorsed or volitional functioning and refers to the extent to which one acts upon personal interests, values and goals. When functioning autonomously, individuals experience a sense of personal choice, volition and psychological freedom (Ryan and Deci 2000). Volition is contrasted with pressured functioning, in which case one feels obliged or seduced to act in a certain way. Although one may feel forced to meet external demands, one can put oneself under pressure as well, for instance by buttressing activity engagement with feelings of guilt, shame or contingent self-worth. In both cases, the behavior is perceived as alien and is accompanied with feelings of inner conflict and stress (Deci and Ryan 2000).

According to SDT, volitional functioning increases as people grow older, at least under supportive conditions (Deci and Ryan 2000). Generally, this claim is confirmed (Sheldon et al. 2006), though not in all life domains (e.g., the academic domain, Gottfried et al. 2001). With regards to the association with psychosocial functioning, autonomy defined as volitional functioning is supposed to yield adaptive outcomes (Deci and Ryan 2000). As demonstrated in several empirical studies, self-endorsed functioning has been found to relate to a wide range of positive outcomes, whereas pressured functioning has been shown to relate to a negative pattern of psychosocial functioning (for overviews, see Ryan et al. 2006; Vansteenkiste et al. 2010). Further, whereas independence is conceived as an agespecific striving that is especially prominent during adolescence, autonomy when defined as volition is supposed to be critical across ages. This is because volition is said to represent an innate human need, whose satisfaction should be beneficial across ages and cultures, a claim that is confirmed increasingly (e.g., Chirkov et al. 2003; Sheldon

In addition, within this view, autonomy is said to yield a different connection with relatedness. Whereas independence sometimes may come at the cost of a warm relationship with the parents (i.e., in case of detachment), volitional functioning is supposed to be fully compatible with relatedness and attachment, and even mutually reinforcing (Ryan et al. 2006; Soenens and Vansteenkiste 2005). Thus, an autonomy-supportive relationship with the parents is supposed to facilitate relatedness, and vice versa. In line with this claim, considerable research has shown already that the security of attachment in adolescents partially depends upon the support of one's volitional functioning, which confirms that both constructs are mutually strengthening rather than mutually exclusive (La Guardia et al. 2000; Ryan and Lynch 1989).

Differentiating and Combining Both Perspectives

Although the differentiation between the different components of independence (i.e., emotional, behavioral, cognitive) is well-accepted in the adolescent literature, we suggest that the distinction between volition versus pressure can complement prevailing viewpoints on adolescent autonomy. Thus, rather than being antagonistic, we conceive them as complementary to provide a more encompassing viewpoint on adolescent autonomy. In line with this, theorists increasingly have stressed that both viewpoints on autonomy are at least distinct, or even orthogonal (Kagitçibasi 2005; Ryan and Deci 2006; Vansteenkiste et al. 2005). Thus, both dimensions of autonomy can be crossed such that four different combinations can be retrieved, which can be done in different domains (e.g., the emotional and behavioral domain, cf. Soenens and Beyers 2012).

To illustrate, in emotional distressing situations, adolescents may turn to the parents (reflecting dependence) because they value their relationship with the parents and feel comfortable doing so (volitional functioning) or because they feel pressured to do so, for instance, when the parents adopt a claiming attitude towards the adolescent (pressured functioning). Likewise, adolescents may decide not to rely on the parents in an emotionally distressing situation (reflecting independence) because they prefer relying on the romantic partner or on peers (volitional functioning) or because they have no other choice as the parents are unavailable (pressured functioning). A similar distinction can be made in the decision-making (i.e., behavioral) domain, that is, adolescents may decide independently because they personally endorse doing so (volitional functioning) or because they have no other choice (pressured functioning). Likewise, adolescents may consult their parents and decide rather dependently because they value their parents' opinion (volitional functioning) or because they feel obliged to do so (pressured functioning).

In line with the above theoretical distinctions, a factor analytical study (Beyers et al. 2003) on two adolescent 
samples pointed to the distinction between "separation" (primarily denoting emotional independence) and "agency" (primarily reflecting self-endorsement and volition), with both factors correlating only slightly. In a recent replication (Lamborn and Groh 2009), the same factorial structure was found. Moreover, when predicting adjustment, separation was unrelated or negatively related to adjustment, while agency was associated positively with psychosocial functioning. The difference between these two viewpoints on autonomy has been supported in several domains, including emerging adults' living conditions (Kins et al. 2009), adolescents' independent decision making (Van Petegem et al. 2012), and parents' support of autonomy (Soenens et al. 2007). In each of these studies, the experience of volition was especially crucial in the prediction of psychosocial adjustment, as compared to the degree of independent functioning as such.

\section{Present Research}

Because previous work only included a limited number of measures tapping into both autonomy definitions, the first aim of the present investigation was to test whether two dimensions (i.e., independence vs. dependence and volition vs. pressure) would underlie a wide range of scales that are stated to measure healthy or pathological aspects of adolescent autonomy. Identifying the core dimensions underlying these autonomy measures would allow for a better grip on their specific meaning, that is, does the measure primarily assess volition (vs. pressure), independence (vs. dependence), or rather a combination of both? Moreover, as the developmental literature on autonomy especially stresses the role of age, we also tested for the robustness of our findings by directly comparing the obtained solution in adolescents of different ages (i.e., middle vs. late adolescents).

A second aim involved investigating the association between the retained dimensions and indicators of psychosocial functioning (i.e., subjective well-being and problem behavior). Based on theorizing and research discussed above (e.g., Van Petegem et al. 2012), we expected the volition dimension to yield adaptive correlates. By contrast, independence was hypothesized to be related to more problem behavior and unrelated to well-being. Additionally, we tested whether the associations between the one dimension and the outcome variables would be qualified by the other dimension. For instance, would it be the case that independence is especially or only beneficial when enacted volitionally? Finally, we also tested the potentially moderating role of age as especially the effects of independent functioning may depend on the age of the participants, that is, independence for younger adolescents may be maladaptive, whereas it may be adaptive for older adolescents (Dishion et al. 2004).

\section{Study 1}

In Study 1, we administered eight measures to investigate the underlying structure of adolescent autonomy (Aim 1). Whereas some measures were expected to tap into either independence versus dependence or volition versus pressure as such, others were expected to constitute a combination of both dimensions. The Method section presents the specific measures as well as what aspects of autonomy they are hypothesized to tap into. As for Aim 2, we inspected associations with indicators of subjective well-being (i.e., self-esteem, depressive symptoms, vitality) and problem behavior (alcohol abuse, deviant behavior).

\section{Method for Study 1}

Participants and Procedure

Participants were 707 Belgian adolescents from 9th through 12th grade, ranging in age between 14 and 20 years $(M=$ 16.5 , $\mathrm{SD}=1.2$ ), reflecting a typical Belgian sample of youngsters. Both genders were distributed almost equally (49 \% boys) and most participants came from intact families (76\%). At school, $60 \%$ of the participants followed an academic track, $23 \%$ a technical and $17 \%$ a vocational track. Data were collected at four different high schools during a regular class period. Participation was voluntary and anonymity was guaranteed through standard informed consent. 691 participants $(97.7 \%)$ provided complete data, resulting in $0.6 \%$ missing data. As Little's (1988) MCARtest produced a normed $\chi^{2}$ of 1.50 , data are likely to be missing at random (Bollen 1989) and are dealt with using multiple imputation with the Expectation Maximization (EM) algorithm (Schafer 1997).

Measures

Questionnaires were selected to cover the hypothetical (combinations of) dimensions as much as possible as well as to include frequently used measures of autonomy (see e.g., Beckert 2012). All questionnaires were completed by the participants in their native language, which is Dutch. Most of the measures were available in Dutch; when this was not the case the scales were translated through a procedure of back translation. Unless otherwise mentioned, the participants answered on a 5-point Likert-type scale, ranging from 1 ("Completely untrue") to 5 ("Completely true"). Total scores for each scale were computed by averaging across the items.

\begin{tabular}{|l|lll|}
\hline & Journal : Large 10964 & Dispatch : 26-10-2012 & Pages : $\mathbf{2 1}$ \\
Article No. : $\mathbf{9 8 4 7}$ & $\square$ LE & $\square$ \\
MS Code : JOYO-2968 & $\checkmark_{\mathrm{CP}}^{\mathrm{TYPESET}}$ \\
\hline
\end{tabular}




\section{Independent Decision Making}

A variation of the Family Decision Making Scale (FDMS, Dornbusch et al. 1985) was administered to assess independent decision making. Participants answered the question "who decides?" about 20 different issues (e.g., choice of clothes, doing chores), thereby using a 5-point scale, ranging from 1 ("Parents alone") to 5 ("I alone"). Higher scores thus indicated more decisional independence. The scale was internally consistent $(\alpha=.85)$. Decisional independence is seen as a prototypical indicator of behavioral independence (Smetana et al. 2004) and, therefore, was expected to load primarily on the dimension reflecting independence.

\section{Emotional Independence}

The Emotional Independence subscale of the Psychological Separation Inventory (PSI, Hoffman 1984) is a measure that is frequently used to assess an adolescent's freedom from excessive needs for parental approval, closeness, and emotional support (e.g., "being away from my parents makes me feel lonely", reverse coded). In the present study, we used a shortened 10-item version of the scale (Luyckx et al. 2006), which had a good reliability $(\alpha=.85)$. As this is an indicator of emotional independence, we expected this measure to load primarily on the dimension of independence as well.

\section{Volition and Pressure}

Further, two subscales of the Self-Determination Scale (SDS, Sheldon et al. 1996) were administered, each consisting of 5 items. Specifically, we measured volition, that is, the extent to which one experiences a sense of choice and self-determination in one's actions (e.g., "I always feel like I choose the things I do"), and pressure, which reflects alienated or controlled functioning (e.g., "I feel that I am rarely myself"). Previous research has shown adequate psychometric properties (e.g., Sheldon et al. 1996; Soenens et al. 2007). In the present study, Cronbach's alpha was .73 for volition and .72 for pressure. These measures were hypothesized to represent the extreme points of the dimension of volition versus pressure.

\section{Emotional Reliance}

A 5-item version of the Emotional Reliance scale (ER, Ryan et al. 2005) tapped into adolescents' willingness to turn to the parents in emotionally distressing situations (e.g., "When I am alone or depressed, I would turn to my parents"). As in previous research (e.g., Deci et al. 2006), the scale was internally consistent $(\alpha=.81)$. Emotional reliance was expected to be an indicator of volitional dependence, that is, willingly choosing to depend on the parents.

\section{Emotional Connectedness}

Adolescents also completed the Emotional Connectedness subscale of the Multigenerational Interconnectedness Scale (MIS, Gavazzi et al. 1999), which measures the extent to which one is psychologically and emotionally dependent upon the parents (e.g., "I choose friends that my parents will like and feel comfortable with"). On the basis of previous research (Dwairy et al. 2006), the scale was limited to 10 items $(\alpha=.79)$. This questionnaire was hypothesized to measure a rather pressured form of dependency, as the items refer primarily to motives such as loyalty, obligation towards the parents and avoiding feelings of guilt.

\section{Engulfment Anxiety}

The participants then completed the 8-item Engulfment Anxiety subscale of the Separation-Individuation Test of Adolescence (SITA, Levine et al. 1986), which assesses the extent to which the parents are perceived as overpowering and intrusively controlling, thereby threatening adolescents' sense of independence and selfhood (e.g., "I can't wait for the day that I can live on my own and am free from my parents"). Previous investigations have shown this subscale to be psychometrically sound (e.g., Kruse and Walper 2008), as was also the case in the present study $(\alpha=.84)$. Engulfment anxiety was expected to reflect a dysfunctional type of autonomy, that is, it was proposed as an indicator of pressured independence.

\section{Oppositional Defiance}

Finally, oppositional defiance was measured using a recently developed scale (Vansteenkiste et al. 2012), which was supplemented by other items measuring highly related constructs (e.g., defiance, Finnegan et al. 1998). The measure assesses compulsive noncompliance and a blunt rejection of the parental authority (e.g., "I do exactly the opposite of what my parents expect me to do"). The final scale consisted of 8 items and had a good reliability ( $\alpha=.85$ ). Conceptually, the construct of oppositional defiance relates closely to the notion of psychological reactance (Brehm 1966). Both are characterized by a tendency to reject parental authority and, as such, involve an orientation towards independence and maximizing distance. The type of independence that is achieved through

\begin{tabular}{lll} 
Journal : Large 10964 & Dispatch : 26-10-2012 & Pages : 21 \\
Article No. : $\mathbf{9 8 4 7}$ & $\square$ LE & $\square$ TYPESET \\
MS Code : JOYO-2968 & $\boldsymbol{V}_{\mathrm{CP}}$ & $\checkmark$ DISK \\
\hline
\end{tabular}


reactance is, however, pressured and conflicted in nature, as it typically involves a blunt rejection of authority against which one is reacting, that is, doing the opposite what is expected (Brehm 1966; Fitzsimons and Lehmann 2004). Because such actions are externally determined and not based upon self-endorsed values and choices, reactance and oppositional defiance were hypothesized to tap into a more dysfunctional form of autonomy.

\section{Subjective Well-Being}

Three scales were administered to measure subjective wellbeing. First, the 5-item global self-worth subscale of the Self-Perception Profile for Adolescents (SPPA, Harter 1988) was administered to tap into feelings of self-worth. The scale had a good reliability in the present study $(\alpha=.82 ; M=3.59, \mathrm{SD}=.79)$. Depressive symptoms were assessed through a 6-item version of the Center for Epidemiologic Studies-Depression Scale (CES-D, Radloff 1977). Adolescents rated how often they experienced symptoms of depression during the past week (e.g., feeling lonely) on a scale from 0 ["Rarely or none of the times (less than one day)"] to 3 ["Most or all of the time (5 to 7 days)"]. The present version of the CES-D was internally consistent $(\alpha=.80 ; M=.59, \mathrm{SD}=.53)$. Finally, vitality was measured through the Subjective Vitality Scale (SVS, Ryan and Frederick 1997). This scale counts 7 items and assesses feelings of energy and vitality (e.g., "Currently, I feel so alive I just want to burst", $\alpha=.88 ; M=3.17$, $\mathrm{SD}=.78)$.

\section{Problem Behavior}

We also assessed problem behavior through two scales. The Deviant Behavior Scale (DBS, Weinmann 1992) was used to tap into rule-breaking behavior. The participants rated their experience with 10 types of deviant behavior (e.g., being involved in fights) during the past 6 months, on a scale from 0 ("Never") to 3 ("Frequently"). The scale had an acceptable reliability $(\alpha=.71 ; M=.50, \mathrm{SD}=.36)$. Additionally, alcohol abuse was assessed through a shortened version of the Alcohol Use Disorders Identification Test (AUDIT, Saunders et al. 1993). The scale consisted of 5 items (e.g., "I sometimes gulp drinks to speed the effect") and had a good reliability $(\alpha=.81 ; M=1.73$, $\mathrm{SD}=.73)$.

\section{Plan of Analysis}

To examine the underlying structure of the autonomy measures (Aim 1), we began with determining and extracting the optimal number of dimensions through principal component analysis (PCA). Then, we made use of orthogonal Procrustes rotation to rotate these dimensions towards an interpretable solution as this is considered a powerful technique for conducting hypothesis-guided rotation (McCrae et al. 1996). Through this technique, dimensions are rotated to minimize the sum of squares of deviations from a hypothesized target matrix (Schönemann 1966). The rotation thus involves a realignment of the position of the axes, without changing their relative position. Such an approach is preferable (1) to the traditional exploratory rotational procedures as the obtained solution not necessarily involves a simple structure (where each variable loads high on one dimension and approximately zero on the other dimensions), and (2) to confirmatory factor analysis, as we were searching for a factor structure of bipolar dimensions (for a further elaboration on these issues, see Hopwood and Donnellan 2010; McCrae et al. 1996). Tucker's Phi values were used to evaluate congruence between the hypothesized and rotated solution, with .85 and higher indicating fair similarity and.95 and higher suggesting strong similarity (Lorenzo-Seva and ten Berge 2006).

In a next step, we tested whether the solution would be valid for both middle and late adolescents. Therefore, we divided our sample in two subsamples, that is, a sample of middle (14-16 years) and late adolescents (17-20 years). Next, the same factor-analytical procedure was repeated in the separate samples, that is, a PCA followed by a Procrustes rotation. To test for the congruence between both obtained solutions, we inspected the similarity in the pattern and the magnitude of the factor loadings through the root mean square (RMS) coefficient and the coefficient of congruence (CC; Rummel 1970, pp. 461-462). The RMS coefficient is proportional to the Euclidean distance between the factor loadings and should be close to zero. The CC represents the cosine of the angle between the factors and the factor loadings, varying between -1.00 (indicating perfect dissimilarity) and 1.00 (indicating perfect similarity).

To examine the relationship with psychosocial functioning (Aim 2), we first explored the effects of the background characteristics (i.e., gender, family structure, education and age) through MANCOVA. Significant effects were controlled for in subsequent series of hierarchical regression analyses, as the control variables were added in the first step and the main predictors, reflecting the two retained dimensions, were added in a second step. Then, in a third step, we added the interaction between the two dimensions to determine whether the association between one dimension and the outcome variables is dependent upon the other dimension. In a final step, we tested for the possibility of moderation by age, by adding two second-order interaction terms (i.e., the interaction between age and each of the two dimensions separately) 
Table 1 Means, standard deviations and correlations among the autonomy measures for Study $1(\mathrm{~N}=707)$

\begin{tabular}{|c|c|c|c|c|c|c|c|c|c|}
\hline & Mean & $\mathrm{SD}$ & 1. & 2. & 3. & 4. & 5. & 6. & 7. \\
\hline 1. Volition & 3.77 & .62 & & & & & & & \\
\hline 2. Emotional reliance & 3.08 & .80 & $.12 * *$ & & & & & & \\
\hline 3. Emotional connectedness & 2.73 & .59 & $-.12 * *$ & $.49 * * *$ & & & & & \\
\hline 4. Pressure & 2.06 & .66 & $-.27 * * *$ & -.06 & $.13 * * *$ & & & & \\
\hline 5. Engulfment anxiety & 2.49 & .81 & $-.27 * * *$ & $-.30 * * *$ & $-.10 * *$ & $.26 * * *$ & & & \\
\hline 6. Oppositional defiance & 2.34 & .67 & -.03 & $-.39 * * *$ & $-.35 * * *$ & $.17 * * *$ & $.52 * * *$ & & \\
\hline 7. Emotional independence & 3.67 & .71 & .02 & $-.58 * * *$ & $-.56 * * *$ & $-.08 *$ & $.26 * * *$ & $.33 * * *$ & \\
\hline 8. Independent decision making & 3.94 & .59 & $.28 * * *$ & $-.15 * * *$ & $-.23 * * *$ & $-.08 *$ & $-.10 * *$ & $.15^{* * * *}$ & $.08 *$ \\
\hline
\end{tabular}

$* p<.05 ; * * p<.01 ; * * * p<.001$

and one third-order interaction term (i.e., the first dimension by the second dimension by age).

\section{Results for Study 1}

Aim 1: Identifying the Structure Underlying the Autonomy Measures

Descriptive statistics and correlations among the autonomy measures are presented in Table 1. PCA was performed on the eight autonomy measures. Inspection of the scree plot clearly yielded evidence for a two-dimensional solution (Cattell 1966), accounting for $55 \%$ of the variance. Consequently, we performed an orthogonal Procrustes rotation to test whether the solution corresponded to the theoretical expectations. Table 2 presents the loadings of the (a) unrotated, (b) hypothesized and (c) rotated solution. Tucker's phi indices suggested fair congruence for both dimensions (.85 and .95 , respectively). To gain further confidence in the obtained factor structure, we repeated the factor analyses making use of the standard orthogonal (VARIMAX) and oblique (PROMAX) rotations. These solutions were found to be highly similar to the solution after Procrustes rotation, with correlations of at least .98 with the corresponding dimensions. Moreover, in the oblique rotation, the two dimensions did not correlate significantly, underscoring their orthogonality.

The solution after Procrustes rotation is depicted in Fig. 1a. Based on Zwick and Velicer (1982), we considered factor loadings higher than .30 as salient. As predicted, both the volition and the pressure subscales of the SDS loaded strongly on one dimension (yet in opposite directions) and nearly zero on the other dimension. The first dimension thus captured the degree to which one experiences a sense or feeling of volition, as opposed to feelings of pressure and coercion, and was labeled as "volition versus pressure". Also as predicted, emotional independence loaded highly positive on the second dimension and approximately zero on the first. However, independent decision making yielded an equally positive loading on both dimensions, ${ }^{1}$ which complicated the interpretation of the second dimension. Because of these interpretational ambiguities, we temporarily refrained from labeling this dimension; yet, we return upon this issue when discussing the present findings. The other measures yielded loadings on the dimensions that were generally in the expected ways. Specifically, both emotional reliance and emotional connectedness especially loaded negative on the second dimension; engulfment anxiety as well as oppositional defiance both loaded negatively on the volition versus pressure dimension and positively on the second dimension.

Next, we tested whether there was congruence between the solutions in our subsamples of middle $(N=309)$ and late adolescents $(N=398)$. Although eyeball inspection already indicated strong similarity between the solutions obtained in both subsamples, we also tested the congruence between the two factor solutions more formally. The RMS coefficients for the two dimensions were both low (i.e., .076 and .062 , respectively), whereas the $\mathrm{CC}$ was twice almost 1.00 (i.e., .988 and .995). These findings underscored the strong congruence between the factor structures in the two subsamples, indicating that the measures yielded similar loadings on the two retained dimensions in the middle adolescent and late adolescent sample.

\footnotetext{
$\overline{1}$ The FDMS comprised issues coming from five different domains 1FL01 (i.e., personal, friendship, prudential, conventional and moral). 1FL02 However, exploratory factor analysis only differentiated between 1FL03 two highly correlated latent factors, one pertaining to personal, 1FL04 friendship and prudential issues and one relating to conventional and 1FL05 moral issues. Subsequent analyses, where we split the FDMS score up 1FL06 into two separate scores, yielded almost identical results, both in 1FL07 terms of the loadings on the two underlying dimensions (cf. Aim 1) as 1FL08 well as the associations with age and psychosocial functioning (cf. 1FL09 Aim 2). Therefore, we chose not to differentiate between these 1FL10 domains.
}

$\begin{array}{lll}\text { Journal : Large 10964 } & \text { Dispatch : 26-10-2012 } & \text { Pages : 21 } \\ \text { Article No. : } \mathbf{9 8 4 7} & \square \text { LE } & \square \text { TYPESET } \\ \text { MS Code : JOYO-2968 } & \sim_{\text {CP }} & \checkmark \text { DISK }\end{array}$


Table 2 Loadings of the unrotated, hypothesized and rotated PCA solution, for Study 1

\begin{tabular}{|c|c|c|c|c|c|c|}
\hline & \multicolumn{2}{|c|}{ Unrotated solution } & \multicolumn{2}{|c|}{ Hypothesized solution } & \multicolumn{2}{|c|}{ Rotated solution } \\
\hline & D1 & D2 & D1 & D2 & D1 & D2 \\
\hline Volition & -.08 & -.71 & 1 & 0 & .71 & .14 \\
\hline Emotional reliance & -.80 & .02 & 1 & -1 & .21 & -.77 \\
\hline Emotional connectedness & -.71 & .39 & -1 & -1 & -.17 & -.80 \\
\hline Pressure & .10 & .64 & -1 & 0 & -.64 & -.09 \\
\hline Engulfment anxiety & .56 & .56 & -1 & 1 & -.70 & .37 \\
\hline Oppositional defiance & .71 & .19 & -1 & 1 & -.39 & .63 \\
\hline Emotional independence & .77 & -.19 & 0 & 1 & -.05 & .79 \\
\hline Independent decision making & .23 & -.53 & 0 & 1 & .44 & .37 \\
\hline
\end{tabular}

$\mathrm{D} 1=$ dimension reflecting volition versus pressure, $\mathrm{D} 2=$ dimension reflecting distance versus proximity
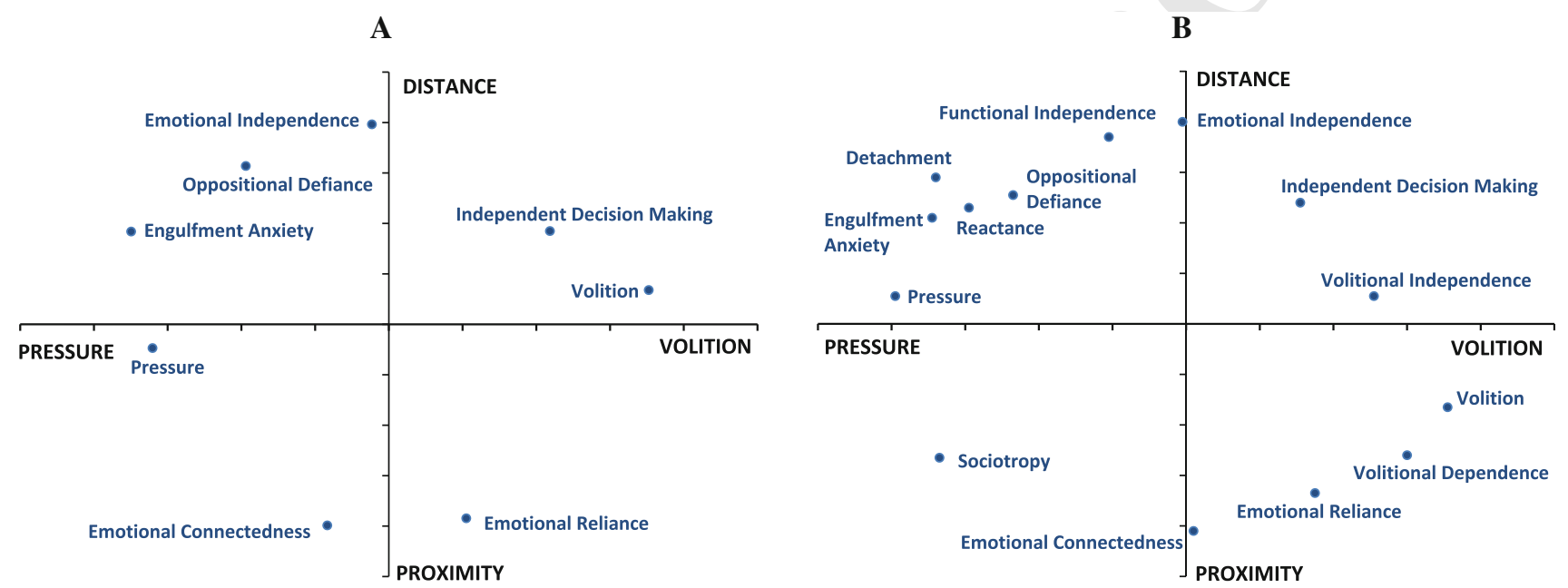

Fig. 1 PCA solution after Procrustes rotation for Study 1 (a) and Study 2 (b)

Aim 2: Associations with Background Characteristics and Adjustment

We first tested the associations with the background characteristics (i.e., gender, family structure, education and age). Multivariate analyses based on Wilk's Lambda indicated a significant main effect of gender $[F(2,693)=13.96$, $\left.p<.001, \eta^{2}=.04\right]$ and age $[F(2,693)=19.47, p<.001$, $\left.\eta^{2}=.05\right]$. There were no significant effects of family structure $[F(6,1386)=1.45, n s]$ or education $[F(4,1386)=$ $1.71, n s]$. Subsequent univariate analyses indicated that boys scored higher on the second dimension $[F(1,694)=$ 25.43, $\left.p<.001, \eta^{2}=.04\right]$. Further, age was found to relate positively to volition $[F(1,694)=38.95, p<.001$, $b=.20]$, whereas it was unrelated to the second dimension $[F(1,694)=.02, n s]$. Hence, we controlled for age and gender in subsequent analyses.

Next, we investigated the association with adjustment through a series of hierarchical regression analyses. The specific correlations with each of the autonomy measures are presented in "Appendix 1". The results of the first two steps of the regression analyses can be found in Table 3. Generally, volition predicted higher scores on the indicators of well-being as well as lower scores on problem behavior. The second dimension predicted slightly less vitality as well as more deviant behavior and alcohol abuse. As for the third step, the interaction between the two dimensions never reached significance, $\Delta F(1,700)$ ranging between .03 and $1.90(p>.05)$. Likewise, adding age as a moderator in a fourth step never added significantly to the prediction of any of the outcome variables, with $\Delta F(3,697)$ ranging between .07 and $2.59(p>.05)$.

\section{Brief Discussion of Study 1}

The first study revealed a number of interesting findings. As for the first aim, initial evidence was obtained for a
637

638

639

640

641

642

643

644

645

646

647

648

649

651 652

\begin{tabular}{|l|lll|} 
Journal : Large 10964 & Dispatch : 26-10-2012 & Pages : 21 \\
Article No. : $\mathbf{9 8 4 7}$ & $\square$ LE & $\square$ TYPESET \\
MS Code : JOYO-2968 & $\sim_{\text {CP }}$ & $\checkmark$ DISK \\
\hline
\end{tabular}


Table 3 Summary of regression analyses predicting adolescents' adjustment in Study 1

\begin{tabular}{|c|c|c|c|c|c|c|c|c|c|c|}
\hline & \multicolumn{6}{|c|}{ Subjective well-being } & \multicolumn{4}{|c|}{ Problem behavior } \\
\hline & \multicolumn{2}{|c|}{ Self esteem } & \multicolumn{2}{|c|}{ Depressive symptoms } & \multicolumn{2}{|l|}{ Vitality } & \multicolumn{2}{|c|}{ Deviant behavior } & \multicolumn{2}{|c|}{ Alcohol abuse } \\
\hline & $b$ & $\Delta R^{2}$ & $b$ & $\Delta R^{2}$ & $b$ & $\Delta R^{2}$ & $b$ & $\Delta R^{2}$ & $b$ & $\Delta R^{2}$ \\
\hline Step 1 & & $.03 * * *$ & & $.03 * * *$ & & .00 & & $.05 * * *$ & & $.08 * * *$ \\
\hline Gender $^{\mathrm{a}}$ & $.13 * *$ & & $-.15 * * *$ & & .02 & & $.21 * * *$ & & $.22 * * *$ & \\
\hline Age & $.09 *$ & & -.04 & & -.06 & & .07 & & $.14 * * *$ & \\
\hline Step 2 & & $.24 * * *$ & & $.18 * * *$ & & $.10 * * *$ & & $.14 * * *$ & $\infty$ & $.08 * * *$ \\
\hline Gender $^{\mathrm{a}}$ & $.11 * *$ & & $-.14 * * *$ & & .02 & & $.15^{* * *}$ & & $.18 * * *$ & \\
\hline Age & -.03 & & .07 & & $-.13 * * *$ & & $.10 * *$ & & $.17 * * *$ & \\
\hline Volition & $.51 * * *$ & & $-.44 * * *$ & & $.32 * * *$ & & $-.12 * *$ & & $-.15 * * *$ & \\
\hline Distance & -.02 & & .04 & & $-.08 *$ & & $.36 * * *$ & & $.24 * * *$ & \\
\hline
\end{tabular}

${ }^{\text {a }} 0=$ female, $1=$ male. $* p<.05 ; * * p<.01 ; * * p<.001$. Standardized regression coefficients are presented

two-dimensional structure underlying the multitude of autonomy measures. This two-dimensional solution was highly similar when comparing between middle and late adolescents. The extraction of these two dimensions helped to gain more precise insight in the meaning of each assessed concept. The pattern of loadings of the different measures clearly suggested that the first dimension could be interpreted as indicative of "volition versus pressure". The interpretation of the second dimension was less clear. This is because the independent decision making scale, which can be considered a straightforward and face valid indicator of independent functioning (Smetana et al. 2004; Van Petegem et al. 2012), failed to load exclusively high on this dimension, instead loading moderately high on both dimensions. Hence, "independence versus dependence" may not be the best label for this second dimension. The observation that oppositional defiance and emotional independence yielded a positive loading on this dimension, whereas emotional reliance and emotional connectedness yielded a negative loading, suggests that this dimension may reflect the felt distance versus proximity in the parentchild relationship (Kagitçibasi 2005). Study 2 was set up to further explore this issue, that is, whether the second dimension could be interpreted in terms of distance versus proximity.

As for the associations with age and adjustment (Aim 2), the dimension reflecting volition versus pressure yielded positive links with well-being and age and slightly negative associations with problem behavior. In contrast, the second dimension was associated with more problem behavior and was generally unrelated to well-being. Contrary to expectations, we found no correlation with age. If this second dimension would capture independence versus dependence, a positive correlation should have emerged, as adolescents' independent functioning is supposed to increase with age (Steinberg 2002). This non-significant association with age equally suggested that a more in-depth investigation of the second dimension is warranted.

\section{Study 2}

The primary aim of Study 2 was to gain further insight in the exact meaning of the second dimension. We attempted to do so in two ways. First, we included a number of additional measures that were assumed to tap into healthy as well as dysfunctional manifestations of autonomy, especially focusing on quadrants that were relatively underrepresented in Study 1. By doing so, we hoped to clarify whether the second dimension reflects the degree of distance vs. proximity in the parent-adolescent relationship or whether another label better describes this dimension. Specifically, we measured sociotropy (Beck 1983), which represents an excessive concern about the opinion of others and a strong reliance on others for maintaining a positive self view. Therefore, sociotropy was hypothesized to reflect a pressured type of proximity in the parent-adolescent relationship (Brenning et al. 2011a). In addition, we administered two newly created measures, which involve a combination of volitional independence and volitional dependence, respectively. Further, in order to cover the different facets of independence better, we also added a measure of functional independence (Beyers and Goossens 2003; Hoffman 1984), which reflects the extent to which one is able to manage personal affairs without help of the parents. Finally, we added two more measures that tap into pathological manifestations of autonomy, that is, detachment and reactance, which were expected to reflect distance from the parents out of pressured reasons. This is because detachment is rooted in mistrust and alienation (Beyers et al. 2003; Lamborn and Groh 2009) and reactant behavior is determined by the rules 
against which one reacts (Brehm 1966; Fitzsimons and Lehmann 2004). In total, then, 14 constructs were included to cover the two dimensions and four quadrants obtained in Study 1.

To further determine the specific meaning of the second dimension, we related the two dimensions to adolescents' attachment representations. We reasoned that attachment theory (Bowlby 1969, 1973) represents a valuable framework for this purpose because autonomous functioning, as indexed by explorative behavior, is said to be rooted in a secure attachment style. Specifically, a critical (yet less studied) function of attachment figures is to provide a secure base, which refers to the provision of guidance to safely explore the environment in a self-confident and autonomous manner (Bowlby 1988; Mikulincer and Shaver 2007a). This function is distinguished from the more wellknown role of attachment figures to serve as a safe haven, which pertains to the provision of safety and support in times of distress. The secure base function seems especially important in adolescence, given the developmental changes characteristic for this period (Allen and Land 1999; Becker-Stoll et al. 2008).

If parents fail to take up these functions, children are said to develop an insecure attachment. Typically, two types of insecure attachment representations are distinguished, that is, avoidant and anxious attachment (e.g., Brennan et al. 1998; Brenning et al. 2011b). Avoidantly attached adolescents tend to downplay the importance of relationships and strive for distance from others. Anxiously attached adolescents, by contrast, are characterized by worries about the availability of others and display a strong ambivalence towards closeness and distance (Brenning et al. 2011b; Mikulincer et al. 2010). Low scores on the two dimensions are considered as indicative of a secure attachment.

If the second dimension would entail independent functioning, we reasoned that it should be unrelated or even positively related to attachment security as secure relationships have been shown to support independent functioning in romantic couples (Feeney 2007) as well as in the mother-adolescent relationship (Allen et al. 2003). Technically, then, the second dimension should relate negatively to both avoidant and anxious attachment. However, if the second dimension would involve distance versus proximity, this dimension should relate primarily to an avoidant attachment, as an orientation towards interpersonal distance is a key feature of this attachment style (Mikulincer and Shaver 2007b). Further, we expected high scores on the volition dimension to relate to low scores on both avoidance and anxiety, as a sensitive and secure attachment has been shown to support self-endorsed functioning in romantic (La Guardia et al. 2000) as well as in the parent-adolescent relationship (Laghi et al. 2009).

\section{Method for Study 2}

Sample and Procedure

Data were collected in two high schools in Belgium. 783 adolescents participated in the study, ranging in age between 14 and 21 years $(M=16.3, \mathrm{SD}=1.3)$. There were slightly more girls (59\%), and most youngsters came from intact families $(79 \%)$. The majority of the participants $(67 \%)$ followed an academic track, $23 \%$ followed a technical track, and $10 \%$ a vocational track. In the present dataset, $16 \%$ of the data was incomplete. These missing data were found to be missing at random (normed $\chi^{2}=1.31$ ) and were estimated through the procedure of multiple estimation using the EM algorithm.

Measures

As in Study 1, participants completed the questionnaire in Dutch and most questionnaires were answered on a 5-point Likert type scale, ranging from 1 ("Completely untrue") to 5 ("Completely true"), unless otherwise mentioned. Different from Study 1, we reformulated the items of some questionnaires towards the parent-child context, such that they all have the same level of focus (Vallerand 1997, 2000).

\section{Independent Decision Making}

As in Study 1, the FDMS (Dornbusch et al. 1985) was used to assess independent decision making. Cronbach's alpha was .88.

\section{Emotional and Functional Independence}

The same 10-item version of the Emotional Independence subscale of the PSI (Hoffman 1984) was administered. In addition, the Functional Independence subscale was used to assess youngsters' ability to manage personal and practical affairs without depending on the parents for help (e.g., "When I am in difficulty I usually call upon my parents to help me out of trouble", reverse coded). We also used a shortened 10-item version (Luyckx et al. 2006) of the functional independence subscale. Both the emotional and the functional independence subscales were internally consistent ( $\alpha=.87$ and .82 , respectively).

802

803

804

805

806

807

808

809

810

811

812

\section{Volition and Pressure}

The two subscales of the SDS (Sheldon et al. 1996) were 814 adapted to assess feelings of volition and pressure in the parent-child relationship. Items of the SDS were reformulated by the first author and, then, were assessed

\begin{tabular}{lll} 
Journal : Large 10964 & Dispatch : 26-10-2012 & Pages : 21 \\
Article No. : $\mathbf{9 8 4 7}$ & $\square$ LE & $\square$ TYPESET \\
MS Code : JOYO-2968 & $\checkmark_{\text {CP }}$ & $\checkmark$ DISK \\
\hline
\end{tabular}


independently by the two other authors. Through discussion, a consensus was reached about the final version. Both the volition (e.g., "When I'm with my parents, I generally make decisions that are based upon my true values and interests.") and pressure subscale (e.g., "When I'm with my parents, I rarely have the feeling I can be myself") consisted of five items. ${ }^{2}$ Cronbach's alpha was .84 for volition and .78 for pressure.

\section{Volitional Dependence and Volitional Independence}

We created two scales to specifically assess volitional dependence and volitional independence. The Volitional Dependence Scale assesses feelings of volition and personal choice when depending upon the parents (e.g., "When I follow the advice of my parents, it feels like a personal choice", "I feel free to ask my parents for help, whenever necessary"; 7 items). The Volitional Independence Scale measures the extent to which the adolescent personally endorses acting and deciding independently (e.g., "I think it's important to first try and solve a problem myself, before relying on my parents for help", "If I don't follow the advice of my parents, it feels like a personal choice"; 8 items). When performing a PCA on these 15 items, the scree plot clearly indicated a two component solution, explaining $49 \%$ of the variance. After performing a Promax rotation, all items clearly loaded onto the expected component (with loadings of at least .47), and approximately zero on the other component. ${ }^{2}$ Cronbach's alpha was .82 for volitional dependence and .76 for volitional independence.

\section{Emotional Reliance}

We assessed emotional reliance on the parents through the same questionnaire as in Study 1, that is, the scale developed by Ryan and colleagues (2006). The scale was internally consistent $(\alpha=.85)$.

\section{Emotional Connectedness}

As in Study 1, we administered the Emotional Connectedness subscale of the MIS (Gavazzi et al. 1999). The scale had an acceptable reliability $(\alpha=.81)$.

\section{Sociotropy}

The participants completed a shortened version of the Sociotropy subscale of the Revised Personal Style Inventory (PSI-II, Robins et al. 1994). The scale originally consisted of 24 items and was designed to assess a sociotropic

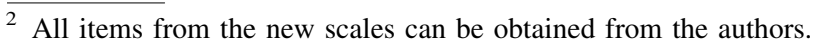

personality style (Beck 1983), which is characterized by a strong dependency on the opinion of others and a striving to please others in order to feel accepted and maintain selfworth. We used an adolescent version of the PSI-II (Brenning et al. 2011a), which was reduced to 10 items on the basis of an unpublished dataset and which was adjusted to the parent-child context (e.g., "I am very sensitive to criticism by my parents"). The brief version correlated strongly with the original version $(r=.87)$. In the present study, the reliability coefficient was acceptable $(\alpha=.76)$.

\section{Detachment}

As in the study of Beyers et al. (2003), the 10-item coolness/rejection subscale of the Relationship with Father/ Mother Questionnaire (RFMQ, Mayseless et al. 1998) was used as an indicator of detachment, as it taps into feelings of alienation and disengagement towards the parents (e.g., "I feel that my parents don't understand me"). The questionnaire was internally consistent $(\alpha=.91)$.

\section{Oppositional Defiance}

As in Study 1, we tapped into oppositional defiance through the same recently developed questionnaire (Vansteenkiste et al. 2012). The scale had a good reliability $(\alpha=.87)$.

\section{Reactance}

880

881

882

883

884

We measured reactance through the Hong Psychological Reactance Scale (HPRS, Hong and Faedda 1996). This scale is based directly upon the theory of psychological reactance (Brehm 1966), measuring a person's trait propensity to experience reactance. This 14-item scale has been shown to be a valid and reliable measure of trait reactance (Shen and Dillard 2005). Items were reworded towards the parent-adolescent context (e.g. "The thought of being dependent on my parents aggravates me"). Cronbach's alpha was .89 .

\section{Engulfment Anxiety}

885

886

887

888

889

890

891

892

893

894

We assessed engulfment anxiety through the same questionnaire as in Study 1, that is, the Engulfment Anxiety subscale of the SITA (Levine et al. 1986). The scale was internally consistent $(\alpha=.86)$.

Attachment

The Experiences in Close Relationships Scale-Revised (ECR-R, Fraley et al. 2000) is a frequently used measure that was originally designed to assess insecure attachment
900

\section{5}

896 897 898 899

901 902 903 
representations in the romantic relationship. In the present study, we used a recently developed version that was adapted to assess attachment to the parents in children and adolescents (ECR-RC; Brenning et al. 2011b). The questionnaire was filled out separately about the mother and father. The ECR-RC consists of two subscales, that is, Avoidance and Anxiety. The Avoidance subscale measures feelings of discomfort with closeness and intimacy (e.g., "I am comfortable being close to my mother/father", reverse coded), the Anxiety subscale taps into a preoccupation about rejection and abandonment (e.g., "I often worry that my mother/father doesn't really love me"). In an unpublished sample of 670 youngsters, both subscales were reduced each to 6 items, by selecting the highest loading items (i.e., $>.70$ ). Both shortened subscales correlated strongly with the original subscales (i.e., .92 and .90 for avoidance and anxiety, respectively) and yielded good reliability coefficients (.88 and .87 , respectively). In the present sample, reliabilities were good for both avoidance $(\alpha=.91$ for mother; $M=3.77, \mathrm{SD}=1.35 ; \alpha=.92$ for father; $M=4.38$, $\mathrm{SD}=1.26)$ and anxiety $(\alpha=.85$ for mother; $M=1.65$, $\mathrm{SD}=.76 ; \alpha=.87$ for father; $M=1.74, \mathrm{SD}=.83$ ).

\section{Subjective Well-Being}

As in Study 1, we used the global self-worth scale of the SPPA to measure self-esteem $(\alpha=.82 ; \quad M=3.56$, $\mathrm{SD}=.80)$ and the CES-D to assess depressive symptoms $(\alpha=.81 ; M=.61, \mathrm{SD}=.57)$. A third indicator of subjective well-being was life satisfaction, measured through the 5-item Satisfaction With Life Scale (SWLS, Diener et al. 1985). This scale measures the extent to which individuals judge their life as satisfying (e.g., "In most ways, my life is close to my ideals"). The scale was internally consistent $(\alpha=.88: M=3.49, \mathrm{SD}=.88)$.

\section{Problem Behavior}

As indicators of problem behavior, the DBS was used again to measure deviant behavior $(\alpha=.73 ; M=.45$, $\mathrm{SD}=.37$ ). Further, we administered the 5-item behavioral conduct subscale of the SPPA (Harter 1988) to tap into adolescents' evaluation of their own behavior $(\alpha=.79$; $M=3.51, \mathrm{SD}=.61)$.

\section{Results for Study 2}

Aim 1: Identifying the Structure Underlying the Autonomy Measures

Table 4 shows the descriptive statistics and correlations among the autonomy measures of Study 2. A PCA on the

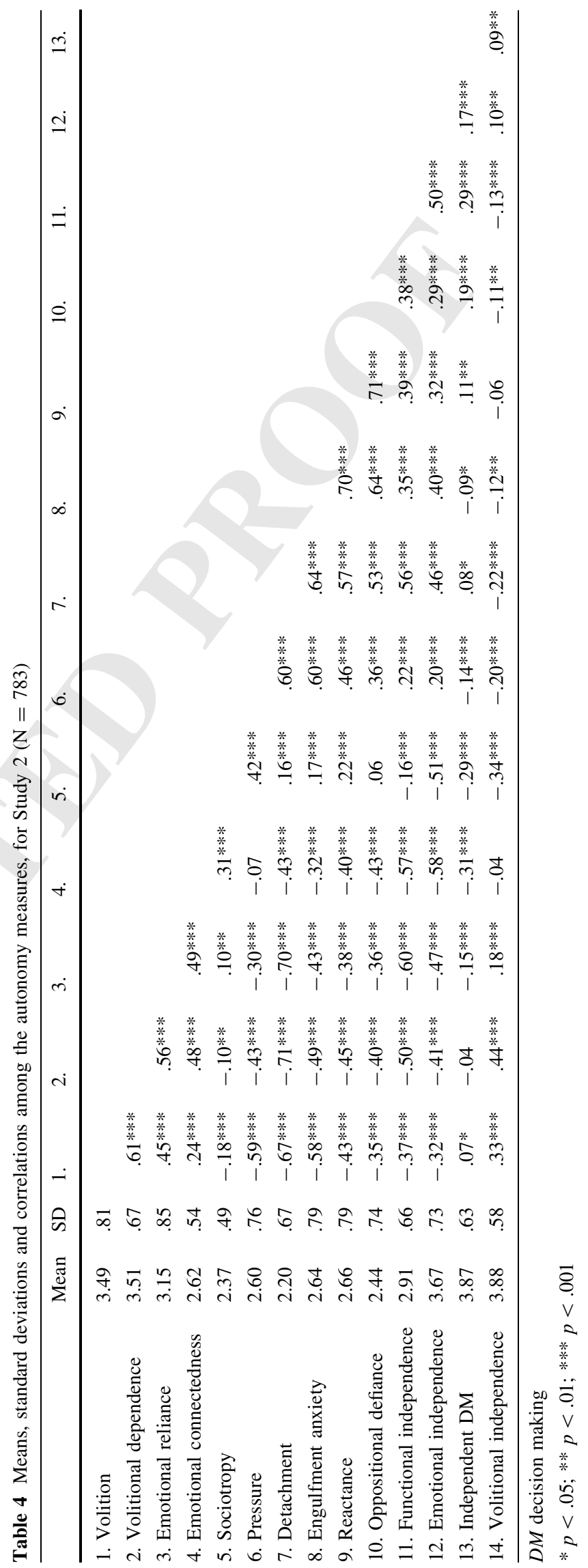

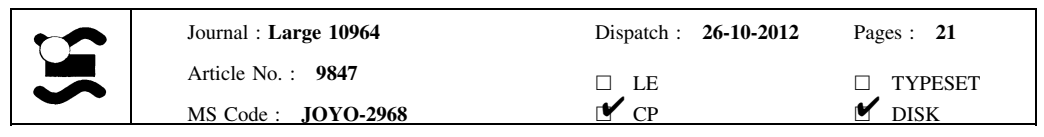


14 scales yielded evidence for a two-dimensional solution, explaining $58 \%$ of the variance in the measures. As in Study 1, the PCA solution was rotated towards a hypothesized solution through an orthogonal Procrustes rotation. The factor loadings of the unrotated, hypothesized and rotated solution are presented in Table 5. Tucker's Phi indices showed good congruence for both dimensions, that is, .91 for Dimension 1 and .94 for Dimension 2. The rotated solution is displayed graphically in Fig. $1 \mathrm{~b}$.

Most of the results were in line with the expectations, with the measures used in Study 1 loading very similarly on the two dimensions. As expected, the first dimension reflected "volition versus pressure", being marked primarily by the scales that assess volitional and coercive functioning in the relationship with the parents. As for the interpretation of the second dimension, results were highly similar to the findings of Study 1. Both the emotional independence subscale and the newly added functional independence subscale of the PSI loaded highly positively on this dimension. Also in line with Study 1, independent decision making loaded positively on this dimension, though on the volition dimension as well. These findings further confirm that the label "independence versus dependence" was not well suited for the second dimension. Instead, the label "distance versus proximity" seemed a better choice which was further confirmed by the loadings of the other newly added measures and the replication of factor loadings of measures used in Study 1. For instance, emotional connectedness again loaded negatively on this dimension. In addition, the newly added scale of sociotropy seemed to tap into a more pressured form of proximity, as it loaded negatively on both dimensions. In contrast, both emotional reliance and the newly created measure of volitional dependence fell in the quadrant tapping into volitional proximity.

Further, the newly added subscale volitional independence especially loaded positively on the volition dimension and only slightly on the distance dimension. Finally, the factor loadings for the other measures were clearly in line with our expectations and also attest the validity of the retained dimensions. As in Study 1, both oppositional defiance and engulfment anxiety entailed a pressured striving for distance. The newly added measures of detachment and reactance loaded negatively on the volition dimension and positively on the distance dimension as well. This underscores that detachment and reactance reflect an orientation towards interpersonal distance from the parents characterized by feelings of pressure and a lack of self-endorsement.

Again, we tested whether the retained solution was valid for both middle and late adolescents. We split the sample into a subsample of middle (14-16 years, $N=446)$ and late adolescents (17-21 years, $N=337)$ and re-ran the factor analysis in each subsample. Again, the comparative statistics yielded strong evidence for similarity between the two factorial solutions, that is, RMS $=.071$ and $\mathrm{CC}=$ .991 for the volition dimension and RMS $=.072$ and $\mathrm{CC}=.991$ for the distance dimension. These findings further bolstered the robustness of the solution.

Aim 2: Associations with Background Characteristics, Attachment and Adjustment

Next, we tested for the associations with the background variables. Significant effects were found for gender $\left[F(2,767)=10.59, \quad p<.001, \eta^{2}=.03\right]$, education

Table 5 Loadings of the unrotated, hypothesized and rotated PCA solution, for Study 2

\begin{tabular}{|c|c|c|c|c|c|c|}
\hline & \multicolumn{2}{|c|}{ Unrotated solution } & \multicolumn{2}{|c|}{ Hypothesized solution } & \multicolumn{2}{|c|}{ Rotated solution } \\
\hline & D1 & D2 & D1 & D2 & D1 & D2 \\
\hline Volition & -.72 & -.30 & 1 & 0 & .71 & -.33 \\
\hline Volitional dependence & -.79 & -.09 & 1 & -1 & .60 & -.52 \\
\hline Emotional reliance & -.73 & .20 & 1 & -1 & .35 & -.67 \\
\hline Emotional connectedness & -.61 & .54 & -1 & -1 & .02 & -.82 \\
\hline Sociotropy & .07 & .85 & -1 & -1 & -.67 & -.53 \\
\hline Pressure & .62 & .50 & -1 & 0 & -.79 & .11 \\
\hline Detachment & .88 & .10 & -1 & 1 & -.68 & .58 \\
\hline Engulfment anxiety & .78 & .22 & -1 & 1 & -.69 & .42 \\
\hline Reactance & .74 & .12 & -1 & 1 & -.59 & .46 \\
\hline Oppositional defiance & .69 & -.01 & -1 & 1 & -.47 & .51 \\
\hline Functional independence & .68 & -.35 & 0 & 1 & -.21 & .74 \\
\hline Emotional independence & .60 & -.54 & 0 & 1 & -.01 & .80 \\
\hline Independent decision making & .14 & -.55 & 0 & 1 & .31 & .48 \\
\hline Volitional independence & -.26 & -.45 & 1 & 1 & .51 & .11 \\
\hline
\end{tabular}

$\mathrm{D} 1=$ dimension reflecting volition versus pressure, $\mathrm{D} 2=$ dimension reflecting distance versus proximity

\begin{tabular}{|c|c|c|c|}
\hline Journal : Large 10964 & Dispatch : & 26-10-2012 & Pages: \\
\hline $\begin{array}{l}\text { Article No. : } \mathbf{9 8 4 7} \\
\text { MS Code : } \quad \text { JOYO-2968 }\end{array}$ & $\begin{array}{l}\square \\
\boldsymbol{V}_{\mathrm{CP}}^{\mathrm{LE}}\end{array}$ & & $\begin{array}{l}\square \text { TYPESET } \\
\boldsymbol{V} \text { DISK }\end{array}$ \\
\hline
\end{tabular}


1011

1012

1013

1014

1015

1016

1017

1018

1019

1020

1021

1022

1023

1024

1025

1026

1027

1028

1029

1030

1031

1032

1033

1034

1035

1036

1037

1038

1039

1040

1041

1042

1043

1044

1045

1046

1047

1048

1049

1050

1051

1052

1053
$\left[F(4,1534)=4.47, \quad p<.01, \quad \eta^{2}=.01\right] \quad$ and $\quad$ age $\left[F(2,767)=10.94, p<.001, \eta^{2}=.03\right]$; family structure was unrelated $[F(6,1534)=1.77, n s]$. Univariate analyses showed that boys scored significantly lower on volition $\left[F(1,768)=13.95, p<.001, \eta^{2}=.02\right]$ and higher on distance $\left[F(1,768)=7.11, p<.01, \eta^{2}=.01\right]$. Adolescents following a technical track scored significantly lower on volition $\left[F(2,768)=7.43, p<.01, \eta^{2}=.02\right]$ as compared to those following an academic or vocational track. Further, similar to the Study 1 findings, age related positively to volition $[F(1,768)=19.74, p<.001, b=.13]$, whereas it was unrelated to distance $[F(1,768)=2.27, n s]$.

To further validate the two dimensions, we inspected partial correlations with parental attachment (controlling for age and gender). In line with our hypotheses, volition related to less avoidant attachment $(r=-.44, p<.001$, and $r=-.24, p<.001$, for mother and father, respectively) and less anxious attachment $(r=-.46, p<.001$, and $r=-.34, p<.001$, respectively). The second dimension related strongly to more avoidant $(r=.59, p<.001$, and $r=.49, p<.001$, respectively) and only slightly to more anxious attachment $(r=.13, p<.001$, and $r=.09$, $p<.05$, respectively). These correlates further justified the label of "distance versus proximity" for the second dimension.

Finally, through a set of hierarchical regression analyses, we tested for the associations with adjustment. The specific correlations with each of the autonomy measures are presented in "Appendix 2". Table 6 presents the results of the first two steps of the regression analyses (i.e., the effects of the control variables and the main effects of volition and distance). Again, volition strongly related to a higher well-being and to less problem behavior. Distance, on the other hand, predicted less life satisfaction, more deviant behavior and a negative behavioral conduct. Analogous to Study 1, we tested for the interaction between distance and volition in a third step and for moderation by age in a fourth step. However, the interaction between the two dimensions never reached significance in the prediction of any of the five outcome variables, $\Delta F(1,775)$ ranging between .04 and $2.73(p>.05)$. The fourth step was never significant either, as $\Delta F(1,772)$ ranged between .61 and $2.45(p>.05)$.

\section{Brief Discussion of Study 2}

The present findings replicated and extended the results of Study 1. Using more autonomy-related measures, which were all formulated with respect to the parent-adolescent relationship, two underlying dimensions emerged again in our sample of middle and late adolescents. Study 2 also provided further evidence for the proposed labeling of the second dimension, reflecting distance versus proximity. This label was justified based on (1) the pattern of loadings of the measures, (2) the strong positive correlations with an avoidant attachment style, and (3) the non-significant correlation with age.

The second aim was to investigate the link with psychosocial functioning. These results were consistent with our hypotheses and the Study 1 findings. Volition clearly related to higher well-being, less problem behavior and a secure attachment, whereas distance related to a somewhat lower well-being, more problem behavior, and an insecure (and especially avoidant) attachment relationship with the parents. Moreover, the variables did not interact in the prediction of the outcomes nor did age play a significant moderating role in these associations.

\section{General Discussion}

As has been alluded to by other scholars (e.g., Silverberg and Gondoli 1996; Zimmer-Gembeck and Collins 2003), the literature on adolescent autonomy seems to suffer from the jingle-jangle fallacy. Frequently, the term autonomy is used as an umbrella term referring to different constructs, each with its own definition, operationalization and assumptions about the role of autonomy in predicting adjustment (cf. the jingle fallacy; Thorndike 1904). Simultaneously, different labels are used sometimes, while in practice the measures tap into the same underlying concept (cf. the jangle fallacy; Kelley 1927). The present investigation aimed at deepening our understanding of the concept and measurement of autonomy. Therefore, we administered a wide array of measures tapping into both healthy and dysfunctional manifestations of autonomy that were selected from a diversity of theories and bodies of literature, including Self-Determination Theory (Ryan and Deci 2000), Separation-Individuation Theory (Blos 1979), Psychological Reactance Theory (Brehm 1966) and the theory on depressogenic personality (Beck 1983). Our goal was to search for the structure underlying these diverse measures and to relate the retained dimension with age, well-being, problem behavior, and attachment style. We found consistent evidence for a two-dimensional structure, involving the dimensions of volition versus pressure and distance versus proximity in the parent-child relationship, which yielded divergent associations with well-being, problem behavior and attachment.

What Is Autonomy All About?

The first retained dimension could be interpreted as "volition versus pressure", which has been studied intensively within Self-Determination Theory (Ryan and Deci
1076

1105

1061

1062

1063

1064

1065

1066

1067

1068

1069

1070

1071

1072

1073

1074

1075

1077

1078

1079

1080

1081

1082

1083

1084

1085

1086

1087

1088

1089

1090

1091

1092

1093

1094

1095

1096

1097

1098

1099

1100

1101

1102

1103

1104

1106

1107

1108 
Table 6 Summary of regression analyses predicting adolescents' adjustment in Study 2

\begin{tabular}{|c|c|c|c|c|c|c|c|c|c|c|}
\hline & \multicolumn{6}{|c|}{ Subjective well-being } & \multicolumn{4}{|c|}{ Problem behavior } \\
\hline & \multicolumn{2}{|c|}{ Self esteem } & \multicolumn{2}{|c|}{ Depressive symptoms } & \multicolumn{2}{|c|}{ Life satisfaction } & \multicolumn{2}{|c|}{ Deviant behavior } & \multicolumn{2}{|c|}{ Behavioral conduct } \\
\hline & $b$ & $\Delta R^{2}$ & $b$ & $\Delta R^{2}$ & $b$ & $\Delta R^{2}$ & $b$ & $\Delta R^{2}$ & $b$ & $\Delta R^{2}$ \\
\hline Step 1 & & $.01 *$ & & $.02 * * *$ & & .00 & & $.03 * * *$ & & $.02 * *$ \\
\hline Gender $^{\mathrm{a}}$ & $.10 * *$ & & $-.14 * * *$ & & .03 & & $.16^{* * *}$ & & $-.13 * * *$ & \\
\hline Age & .02 & & $.07 *$ & & -.05 & & $.10 * *$ & & .02 & \\
\hline Step 2 & & $.19 * * *$ & & $.14 * * *$ & & $.22 * * *$ & & $.08 * * *$ & & $.33 * * *$ \\
\hline Gender $^{\mathrm{a}}$ & $.16^{* * *}$ & & $-.19 * * *$ & & $.11 * *$ & & $.11 * *$ & & -.04 & \\
\hline Age & -.04 & & $.12 * * *$ & & $-.10 * *$ & & $.11 * *$ & & -.02 & \\
\hline Volition & $.44 * * *$ & & $-.38 * * *$ & & $.41 * * *$ & & $-.17 * * *$ & & $.41 * * *$ & \\
\hline Distance & -.06 & & .06 & & $-.24 * * *$ & & $.23 * * *$ & & $-.42 * * *$ & \\
\hline
\end{tabular}

${ }^{\mathrm{a}} 0=$ female, $1=$ male. $* p<.05 ; * * p<.01 ; * * * p<.001$. Standardized regression coefficients are presented

2000). This dimension involves acting upon personally endorsed values and interests, which typically is accompanied by experiences of choice, volition and psychological freedom. Pressure, by contrast, involves coercive functioning, which often is accompanied with an internal conflict and feelings of alienation from one's sense of self. In line with our expectations, volition clearly yielded beneficial correlates with adolescents' functioning as it related strongly to higher well-being, less problem behavior and a secure attachment to the parents. Further, volition also related positively with age, which indicates that, on average, older adolescents increasingly tend to experience a greater sense of psychological freedom and personal choice in their relationship with their parents.

As for the second dimension, we hypothesized that this dimension would capture adolescents' independent versus dependent functioning as this viewpoint on autonomy dominates in developmental as well as cross-cultural frameworks on autonomy (e.g., Blos 1979; Markus and Kitayama 1991; Smetana et al. 2004). Yet, the current results suggested that the second dimension could be labeled as "distance versus proximity", which involves the degree of interpersonal distance in the parent-child relationship. Several findings favored this labeling. First, the pattern of loadings of the indicators of independence was rather equivocal. For instance, even though independent decision making is considered a straightforward measure of independence (Smetana et al. 2004), it loaded equally high on both dimensions. Second, distance versus proximity related strongly to an avoidant attachment style, which is characterized by a strong desire for interpersonal distance and an avoidance of closeness and intimacy. Third, as adolescents grow older, they are supposed to function increasingly independently (Steinberg 2002). Yet, no positive association with age was obtained. Further, although independence is supposed to yield beneficial correlates when adolescents are older (cf. Smetana et al.
2004), the retained dimension did not interact with age in the prediction of our outcome variables.

As for the associations with the outcomes, distance related positively to problem behavior and an insecure attachment, while being unrelated or related negatively to well-being. Taken together, then, when predicting subjective well-being, the most pertinent question is not so much whether one maintains proximity or seeks distance in the parent-child relationship. Much more critical is the question whether one experiences a sense of volition and choice as opposed to pressure and coercion, regardless of the degree of distance versus proximity as such.

Broader Operational, Theoretical and Clinical Implications

First, the present findings raise questions about the names of certain autonomy scales, as these names might not be well capturing their intended content. For instance, the Emotional and Functional Independence subscales of the PSI (Hoffman 1984) do not seem to tap into adolescents' independent functioning as their labels suggest given their null-relationship with age and their low association with independent decision making. Instead, the current findings suggest that these measures rather assess a distant and avoidant stance towards the parents. In a similar fashion, the label of the Emotional Connectedness subscale of the MIS (Gavazzi et al. 1999) suggests that the scale measures a positive bond and a willing reliance on the parents. Although the current findings suggest that this scale assesses general feelings of loyalty and proximity to the parents as such, it remains unclear whether this proximity is willingly sought or maintained (e.g., valuing the opinion of your parents) or rather coercive in nature (e.g., driven by fear for rejection). In short, the names of some scales do not seem to match with their exact operationalization, which may create confusion in the field and hamper systematic progress.
1158

1159

1160

1161

1162

1163

1164

1165

1166

1167

1168

1169

1170

1171

1172

1173

1174

1175

1176

1177

1178

1179

1180 
1181

1182

1183

1184

1185

1186

1187

1188

1189

1190

1191

1192

1193

1194

1195

1196

1197

1198

1199

1200

1201

1202

1203

1204

1205

1206

1207

1208

1209

1210

1211

1212

1213

1214

1215

1216

1217

1218

1219

1220

1221

1222

1223

1224

1225

1226

1227

1228

1229

1230

1231

1232

1233
Hence, it seems of crucial importance to think critically about the measurement when conducting future studies on autonomy; researchers need to be cautious as there might be a gap between the label and the type of autonomy the measure actually taps in. Thus, researchers would do well to reflect critically on which aspects of autonomy they aim to tap into and select a valid measure accordingly.

Second, the present findings also shed light on what independence is all about. Independent functioning (e.g., as indicated by youth alone decision making) implies taking some distance from the parents as one is not relying upon the advice of the parents, a tendency that—on average—-seems accompanied by feelings of volition and self-endorsement. This interpretation seems justified by the moderate positive loading of independent decision making on both dimensions. Thus, the present findings suggest that independence and volition are clearly distinct, yet not fully orthogonal. This finding is consistent with past work showing that an independent living situation in emerging adults is on average reflective of a volitional choice (Kins et al. 2009).

Third, the current results provide insight into the reasons why certain autonomy-related constructs relate positively or negatively to adjustment. For instance, although past research (e.g., Brenning et al. 2011a) found sociotropy (Beck 1983) to relate to maladjustment, the present results may suggest why. That is, the relationship exists not so much because sociotropy yields a focus on keeping proximity with others per se, but rather because the proximity-maintenance comes with feelings of pressure and obligation. Similarly, the likely reason why reactance (Brehm 1966) yields maladjustment is because it is characterized by a pressured and alienating form of distance seeking. So, even though reactant and oppositional behavior is oriented towards reestablishing "freedom" by means of creating distance (Brehm 1966), the present findings suggest that the very act of seeking distance is not accompanied by feelings of psychological freedom, on the contrary.

Fourth, the present findings also help to answer the question of whether autonomy and relatedness form compatible or antagonistic forces (Cooper and Grotevant 2011). Whereas distance potentially yields tension with relatedness, volition is fully compatible with relatedness. This is because when adolescents experience a strong sense of psychological freedom in the interaction with their parents, they will feel connected to them as well. Hence, the challenge for adolescents is not so much to balance their striving for independence with their striving for closeness, but rather to find ways to volitionally seek distance or to volitionally remain proximal to their parents. Similarly, the present results also emasculate the statement of certain separation-individuation theorists (e.g., Freud 1958) about interpersonal distance and even detachment being normative and necessary for adolescents. These findings rather suggest that successful separation-individuation from the parents does not entail a physical or interpersonal movement away from the parents (Boles 1999). Much more critical is the maintenance of a sense of volition during this transformation process of the parent-child relationship.

Finally, the current studies are also clinically important, because issues regarding proximity and distance frequently form the direct or indirect basis for parent-adolescent conflicts. The present findings suggest that counselors may attend to the qualitative reasons why youngsters are seeking to expand their boundaries or why they remain proximal to their parents. Similarly, when rearing an adolescent, parents may want to foster volitional functioning, regardless of whether the adolescent is oriented towards increasing independence or rather wants to stay within close boundaries. Such volitional functioning can be supported through empathy, giving meaningful choice when possible and providing a rationale when choice is limited (Soenens et al. 2007).

Limitations and Suggestions for Future Research

Several limitations need to be acknowledged. First, the included autonomy measures do not encompass the full range of existing scales. It may be interesting to administer other autonomy measures along with certain measures included herein. We believe the present study provides a framework for deriving hypotheses about what aspects of autonomy a measure may tap into and about the functional role of the assessed construct. For instance, in addition to sociotropy, Beck (1983) proposed "autonomy" as a second depressogenic vulnerability factor. Within this perspective, autonomy is defined as a strong need for control and a compulsive focus on self-reliance. On the basis of the present findings, we would hypothesize this measure of autonomy to fall in the quadrant of pressured distance. Typically, developmental theorists also point to the existence of a cognitive type of independence (Zimmer-Gembeck and Collins 2003), which is defined as the capacity for independent thought (Beckert 2007). Even though the study of cognitive independence is more limited, the notion is gaining increasing attention in the developmental literature (see e.g., Lee et al. 2010). Therefore, future research should focus explicitly on this component as well as by examining how cognitive independence relates to the present model.

Moreover, the present investigation was limited to one specific context (i.e., the parent-child relationship) and a specific sample (i.e., middle and late adolescents from a Western country). One may raise the question of whether a similar underlying structure and a similar set of correlates will emerge, when changing the age category, the culture or the domain of focus. We hypothesize that, under certain conditions, correlates of the distance dimension may be different. For instance, high scores on distance may be

\begin{tabular}{|l|lll|}
\hline & Journal : Large 10964 & Dispatch : 26-10-2012 & Pages : $\mathbf{2 1}$ \\
Article No. : $\mathbf{9 8 4 7}$ & $\square_{\mathrm{CP}}^{\mathrm{LE}}$ & $\square$ & $\checkmark_{\text {DISK }}^{\text {TYPESET }}$ \\
\hline
\end{tabular}


1285

1286

1287

1288

1289

1290

1291

1292

1293

1294

1295

1296

1297

1298

1299

1300

1301

1302

1303

1304

1305

1306

1307

1308

1309

1310

1311

1312

1313

1314

1315

1316

1317

1318

1319

1320

1321 even more detrimental in early adolescence (cf. Dishion et al. 2004). Similarly, proximity might yield more beneficial correlates in a collectivistic or relatedness-oriented culture (Markus and Kitayama 1991) or in people with an interdependent (vs. independent) self-construal; it might even vary as a function of the situation (cf. Lalwani and Shavitt 2009). However, SDT assumes volition to be a core human need (Deci and Ryan 2000) and expects it to yield beneficial outcomes across cultures. An explicit test of the present model across cultures is needed, however, to truly confirm this proposition.

The present investigation also was limited to the parentadolescent context. However, peers also play an important role in the development of adolescent autonomy. For instance, Daddis (2011) recently showed that perceptions of peers as being more independent predicted desires for increased independence. Fuligni and Eccles (1993) showed that restrictive and controlling parenting (which inhibits volitional functioning) predicted an increase in a compulsive orientation towards peers. These findings indicate that both worlds (i.e., autonomy in the parent and peer context) are connected. Even more broadly, Larson (2000) and Allen et al. (1997) discuss the ways in which youth organizations and intervention programs may influence adolescents' autonomous functioning. Hence, future research may want to document how youngsters' autonomy development is embedded in a broader social context.

A final major limitation of the present study concerns its cross-sectional nature. Therefore, one cannot draw any conclusions about the direction of effects regarding, for instance, the association between volition and well-being. A longitudinal design would allow testing for the direction of effects between both dimensions and psychosocial functioning. Moreover, such a design would allow investigating age-related changes in the retained dimensions as well. Hence, longitudinal follow-ups of the present investigation seem advisable.
Conclusion

Although the dynamics of adolescent autonomy have received a lot of attention in the field of adolescent psychology, both at the theoretical and empirical levels, few studies have been undertaken to search for the structure underlying these diverse measures. In our view, the current investigation represents an important step towards the clarification of the exact meaning, the measurement and the functional role of autonomy. Specifically, a two-dimensional structure was obtained, with the first dimension pertaining to the degree to which adolescents experience a sense of volition and psychological freedom or rather pressure and coercion in the parent-child relationship, whereas the second dimension reflected the degree of interpersonal distance versus proximity in the parent-child relationship. We believe this two-dimensional structure represents a more encompassing model for the study of autonomy, which allows scholars to draw more accurate conclusions about the exact meaning and measurement of adolescent autonomy and counselors to gain better insight into which type of autonomy adolescents (fail to) display.

Acknowledgments We would like to thank Bart Soenens and Loes Keijsers for their useful comments on earlier drafts of the manuscript. SVP coordinated the project, conceived of the study, participated in the design, coordinated the data collection, analyzed the data and drafted the manuscript. MV and WB participated in the study design, helped in the collection and interpretation of the data and in drafting the manuscript. All authors read and approved the final manuscript. This research was supported by Grant 3F009009 from the Fund for Scientific Research Flanders.

Conflict of interest The authors declare that they have no conflict of interest.

\section{Appendix 1}

1354

See Table 7.

1355

Table 7 Correlations between autonomy measures and psychosocial functioning in Study 1

\begin{tabular}{|c|c|c|c|c|c|c|}
\hline & Age & Self esteem & Depressive symptoms & Vitality & Deviant behavior & Alcohol abuse \\
\hline Volition & $.24 * * *$ & $.33 * * *$ & $-.19 * * *$ & $.21 * * *$ & .03 & .00 \\
\hline Emotional reliance & .07 & $.12 * *$ & -.07 & $.10 *$ & $-.29 * * *$ & $-.21 * * *$ \\
\hline Emotional connectedness & .03 & -.06 & .04 & .05 & $-.24 * * *$ & $-.14 * * *$ \\
\hline Pressure & -.04 & $-.57 * * *$ & $.47 * * *$ & $-.30 * * *$ & .04 & $.12 * *$ \\
\hline Engulfment anxiety & $-.13 * *$ & $-.25 * * *$ & $.31 * * *$ & $-.16^{* * *}$ & $.18 * * *$ & $.14 * * *$ \\
\hline Oppositional defiance & $-.09 *$ & $-.17 * * *$ & $.19 * * *$ & $-.13 * *$ & $.39 * * *$ & $.29 * * *$ \\
\hline Emotional independence & $.08 *$ & -.03 & .01 & $-.10 * *$ & $.27 * * *$ & $.22 * * *$ \\
\hline Independent decision making & $.25 * * *$ & $.09 *$ & $-.09 *$ & .04 & $.16^{* * *}$ & $.17 * * *$ \\
\hline Volition versus pressure & $.24 * * *$ & $.51 * * *$ & $-.43 * * *$ & $.29 * * *$ & $-.08 *$ & $-.09 *$ \\
\hline Distance versus proximity & .03 & .00 & .02 & $-.08 *$ & $.39 * * *$ & $.28 * * *$ \\
\hline
\end{tabular}

$* p<.05 ; * * p<.01 ; * * * p<.001$

\begin{tabular}{|l|lll|}
\hline Journal : Large 10964 & Dispatch : 26-10-2012 & Pages : 21 \\
Article No. : $\mathbf{9 8 4 7}$ & $\square$ LE & $\square$ TYPESET \\
MS Code : JOYO-2968 & $\checkmark$ CP & $\checkmark$ DISK \\
\hline
\end{tabular}


Appendix 2

See Table 8 .

Table 8 Correlations between autonomy measures and psychosocial functioning in Study 2

\begin{tabular}{|c|c|c|c|c|c|c|}
\hline & Age & Self esteem & Depressive symptoms & Life satisfaction & Deviant behavior & Behavioral conduct \\
\hline Volition & $.09 * *$ & $.27 * * *$ & $-.22 * * *$ & $.41 * * *$ & $-.12 * * *$ & $.34 * * *$ \\
\hline Volitional dependence & $.07 *$ & $.23 * * *$ & $-.19 * * *$ & $.36 * * *$ & $-.19 * * *$ & $.44 * * *$ \\
\hline Emotional reliance & -.05 & $.25 * * *$ & $-.27 * * *$ & $.39 * * *$ & $-.24 * * *$ & $.42 * * *$ \\
\hline Emotional connectedness & .02 & .00 & .00 & $.14 * * *$ & $-.15 * * *$ & $.31 * * *$ \\
\hline Sociotropy & -.04 & $-.26 * * *$ & $.18 * * *$ & $-.09 *$ & .05 & $-.09 * *$ \\
\hline Pressure & $-.08 *$ & $-.30 * * *$ & $.23 * * *$ & $-.32 * * *$ & $.11 * *$ & $-.27 * * *$ \\
\hline Detachment & .03 & $-.42 * * *$ & $.36 * * *$ & $-.49 * * *$ & $.18 * * *$ & $-.46 * * *$ \\
\hline Engulfment anxiety & $-.10 * *$ & $-.32 * * *$ & $.27 * * *$ & $-.34 * * *$ & $.22 * * *$ & $-.45 * * *$ \\
\hline Reactance & $-.12 * *$ & $-.25 * * *$ & $.21 * * *$ & $-.26 * * *$ & $.28 * * *$ & $-.48 * * *$ \\
\hline Oppositional defiance & $-.14 * * *$ & $-.14 * * *$ & $.13 * * *$ & $-.17 * * *$ & $.38 * * *$ & $-.69 * * *$ \\
\hline Functional independence & .07 & $-.10 * *$ & $.10 * *$ & $-.27 * * *$ & $.31 * * *$ & $-.44 * * *$ \\
\hline Emotional independence & .04 & -.07 & -.01 & $-.20 * * *$ & $.12 * *$ & $-.21 * * *$ \\
\hline Independent decision making & $.27 * * *$ & $.11 * *$ & -.04 & .00 & $.22 * * *$ & $-.19 * * *$ \\
\hline Volitional independence & $.08 *$ & $.16^{* * *}$ & $-.14 * * *$ & $.18 * * *$ & $-.15^{* * *}$ & $.25 * * *$ \\
\hline Volition versus Pressure & $.14 * * *$ & $.41 * * *$ & $-.33 * * *$ & $.38 * * *$ & $-.17 * * *$ & $.41 * * *$ \\
\hline Distance versus proximity & .07 & -.06 & .06 & $-.25 * * *$ & $.24 * * *$ & $-.41 * * *$ \\
\hline
\end{tabular}

$* p<.05 ; * * p<.01 ; * * * p<.001$

\section{References}

Allen, J. P., Hauser, S. T., Bell, K. L., \& O'Connor, T. G. (1994). Longitudinal assessment of autonomy and relatedness in adolescent family interactions as predictors of adolescent ego development and self-esteem. Child Development, 65, 179-194.

Allen, J. P., \& Land, D. (1999). Attachment in adolescence. In J. Casssidy \& P. R. Shaver (Eds.), Handbook of attachment: Theory, research and clinical applications (pp. 319-335). New York: Guilford.

Allen, J. P., McElhaney, K. B., Land, D. J., Kuperminc, G. P., Moore, C. W., O'Beirne-Kelly, H., et al. (2003). A secure base in adolescence: Markers of attachment security in the motheradolescent relationship. Child Development, 74, 292-307.

Allen, J. P., Philliber, S., Herrling, S., \& Kuperminc, G. P. (1997). Preventing teen pregnancy and academic failure: Experimental evaluation of a developmentally based approach. Child Development, 68, 729-742.

Beck, A. T. (1983). Cognitive treatment of depression: New perspectives. In P. J. Clayton \& J. E. Barrett (Eds.), Treatment of depression: Old controversies and new approaches (pp. 265-290). New York: Raven Press.

Becker-Stoll, F., Fremmer-Bombik, E., Wartner, U., Zimmerman, P., \& Grossmann, K. E. (2008). Is attachment at ages 1, 6 and 16 related to autonomy and relatedness behavior of adolescents in interaction towards their mothers? International Journal of Behavioral Development, 32, 372-380.

Beckert, T. E. (2007). Cognitive autonomy and self evaluation in adolescence: A conceptual investigation and instrument development. North American Journal of Psychology, 9, 579-594.

Beckert, T. E. (2012). Adolescent autonomy and its assessment. In R. J. R. Levesque (Ed.), Encyclopedia of adolescence (pp. 241-247). New York: Springer.
Beyers, W., \& Goossens, L. (1999). Emotional autonomy, psychosocial adjustment and parenting: Interactions, moderating and mediating effects. Journal of Adolescence, 22, 753-769.

Beyers, W., \& Goossens, L. (2003). Psychological separation and adjustment to university: Moderating effects of gender, age, and perceived parenting style. Journal of Adolescent Research, 18, 363-382.

Beyers, W., Goossens, L., Vansant, I., \& Moors, E. (2003). A structural model of autonomy in middle and late adolescence: Connectedness, separation, detachment, and agency. Journal of Youth and Adolescence, 32, 351-365.

Blos, P. (1979). The adolescent passage. Madison, CT: International Universities Press.

Boles, S. A. (1999). A model of parental representations, second individuation, and psychological adjustment in late adolescence. Journal of Clinical Psychology, 55, 497-512.

Bollen, K. (1989). Structural equation modeling with latent variables. New York: Wiley.

Bowlby, J. (1969). Attachment and loss: Vol. 1. Attachment. New York: Basic Books.

Bowlby, J. (1973). Attachment and loss: Vol. 2. Separation and anxiety. New York: Basic Books.

Bowlby, J. (1988). A secure base. New York: Basic Books.

Brehm, J. W. (1966). A theory of psychological reactance. San Diego, CA: Academic Press.

Brennan, K. A., Clark, C. L., \& Shaver, P. R. (1998). Self-report measurement of adult attachment : An integrative overview. In J. A. Simpson \& W. S. Rhodes (Eds.), Attachment and close relationships (pp. 46-76). London: Guilford Press.

Brenning, K., Soenens, B., Braet, C., \& Bosmans, G. (2011a). The role of depressogenic personality and attachment in the intergenerational similarity of depressive symptoms: A study with
1391

1392

1393

1394

1395

1396

1397

1398

1399

1400

1401

1402

1403

1404

1405

1406

1407

1408

1409

1410

1411

1412

1413

1414

1415

1416

1417

1418

1419

1420

1421

1422

1423

\begin{tabular}{l|lll|} 
Journal : Large 10964 & Dispatch : 26-10-2012 & Pages : 21 \\
Article No. : $\mathbf{9 8 4 7}$ & $\square$ LE & $\square$ TYPESET \\
MS Code : JOYO-2968 & $\boldsymbol{V}_{\mathrm{CP}}$ & $\boldsymbol{\sim}$ DISK \\
\hline
\end{tabular}


1424

1425

1426

1427

1428

1429

1430

1431

1432

1433

1434

1435

1436

1437

1438

1439

1440

1441

1442

1443

1444

1445

1446

1447

1448

1449

1450

1451

1452

1453

1454

1455

1456

1457

1458

1459

1460

1461

1462

1463

1464

1465

1466

1467

1468

1469

1470

1471

1472

1473

1474

1475

1476

1477

1478

1479

1480

1481

1482

1483

1484

1485

1486

1487

1488 early adolescents and their mothers. Personality and Social Psychology Bulletin, 37, 284-297.

Brenning, K., Soenens, B., Braet, C., \& Bosmans, G. (2011b). An adaptation of the Experiences in Close Relationships ScaleRevised for use with children and adolescents. Journal of Personal and Social Relationships, 28, 1048-1072.

Cattell, R. B. (1966). The scree test for the number of factors. Multivariate Behavioral Research, 1, 245-276.

Chirkov, V., Ryan, R. M., Kim, Y., \& Kaplan, U. (2003). Differentiating autonomy from individualism and independence: A self-determination theory perspective on internalization of cultural orientations and well-being. Journal of Personality and Social Psychology, 84, 97-110.

Collins, W. A., \& Repinski, D. J. (1994). Relationships during adolescence: Continuity and change in interpersonal perspective. In R. Montemayor, G. R. Adams, \& T. P. Gullotta (Eds.), Personal relationships during adolescence. Thousand Oaks, CA: Sage.

Cooper, C. R., \& Grotevant, H. D. (2011). Autonomy or connections? Identities as intergenerational projectsa. In C. R. Cooper (Ed.), Multiple worlds: Cultures, identities, and pathways to college. New Yor, NY: Oxford University Press.

Daddis, C. (2011). Desire for increased autonomy and adolescents' perceptions of peer autonomy: "Everyone else can; why can't I?". Child Development, 82, 1310-1326.

Darling, N., Cumsille, P., \& Martinez, M. L. (2008). Individual differences in adolescents' beliefs about legitimacy of parental authority and their own obligation to obey. Child Development, $79,1103-1118$.

Deci, E. L., La Guardia, J. G., Moller, A. C., Scheiner, M. J., \& Ryan, R. M. (2006). On the benefits of giving as well as receiving autonomy support: Mutuality in close friendships. Personality and Social Psychology Bulletin, 32, 313-327.

Deci, E. L., \& Ryan, R. M. (2000). The "what" and "why" of goal pursuits: Human needs and the self-determination of behavior. Psychological Inquiry, 11, 227-268.

Diener, E., Emmons, R. A., Larsen, R. J., \& Griffin, S. (1985). The Satisfaction with Life Scale. Journal of Personality Assessment, 49, 71-75.

Dishion, T. J., Nelson, S. E., \& Bullock, B. M. (2004). Premature adolescent autonomy: Parent disengagement and deviant peer process in the amplification of problem behavior. Journal of Adolescence, 27, 515-530.

Dornbusch, S. M., Carlsmith, J. M., Bushwall, S. J., Ritter, P. L., Leiderman, H., Hastorf, A. H., et al. (1985). Single parents, extended households, and the control of adolescents. Child Development, 56, 326-341.

Dwairy, M., Achoui, M., Abouserie, R., \& Farah, A. (2006). Adolescent-family connectedness among Arabs: A second cross-regional research study. Journal of Cross-Cultural Psychology, 37, 248-261.

Feeney, B. C. (2007). The dependency paradox in close relationships: Accepting dependence promotes independence. Journal of Personality and Social Psychology, 92, 268-285.

Finnegan, R. A., Hodges, E. V. E., \& Perry, D. G. (1998). Victimization by peers: Associations with children's reports of mother-child interaction. Journal of Personality and Social Psychology, 75, 1076-1086.

Fitzsimons, G. J., \& Lehmann, D. R. (2004). Reactance to recommendations: When unsolicited advice yields contrary responses. Marketing Science, 23, 82-94.

Fraley, R. C., Waller, N. G., \& Brennan, K. A. (2000). An item response theory analysis of self-report measures of adult attachment. Journal of Personality and Social Psychology, 78, $350-365$.
Freud, A. (1958). Adolescence. In A. Freud (Ed.), The writings of Anna Freud: Research at the Hampstead Child-Therapy Clinic and other papers (1956-1965) (Vol. 5, pp. 136-166). New York: International Universities Press.

Fuligni, A. J., \& Eccles, J. S. (1993). Perceived parent-child relationships and early adolescents orientation toward peers. Developmental Psychology, 29, 622-632.

Garber, J., \& Little, S. A. (2001). Emotional autonomy and adolescent adjustment. Journal of Adolescent Research, 16, 355-371.

Gavazzi, S. M., Sabatelli, R. M., \& Reese-Weber, M. (1999). Measurement of financial, functional, and psychological connections in families: Conceptual development and empirical use of the Multigenerational Interconnectedness Scale. Psychological Reports, 84, 1361-1371.

Gottfried, A. E., Fleming, J. S., \& Gottfried, A. W. (2001). Continuity of academic intrinsic motivation from childhood through late adolescence: A longitudinal study. Journal of Educational Psychology, 93, 3-13.

Harter, S. (1988). Manual for the self-perception profile for adolescents. Denver, CO: University of Denver.

Hoffman, J. A. (1984). Psychological separation of late adolescents from their parents. Journal of Counseling Psychology, 31, $170-178$.

Hong, S. M., \& Faedda, S. (1996). Refinement of the Hong Psychological Reactance Scale. Educational and Psychological Measurement, 56, 173-182.

Hopwood, C. J., \& Donnellan, M. B. (2010). How should the internal structure of personality measures be evaluated? Personality and Social Psychology Review, 14, 332-346.

Kagitçibasi, C. (2005). Autonomy and relatedness in cultural context: Implications for self and family. Journal of Cross-Cultural Psychology, 36, 403-422.

Kelley, T. L. (1927). Interpretation of educational measurements. New York, NY: World book.

Kins, E., Beyers, W., Soenens, B., \& Vansteenkiste, M. (2009). Patterns of home leaving and subjective well-being in emerging adulthood: The role of motivational processes and parental autonomy support. Developmental Psychology, 45, $1416-1429$

Kruse, J., \& Walper, S. (2008). Types of individuation in relation to parents: Predictors and outcomes. International Journal of Behavioral Development, 32, 390-400.

Kuhn, E. S., \& Laird, R. D. (2011). Individual differences in early adolescents' beliefs in the legitimacy of parental authority. Developmental Psychology, 47, 1353-1365.

La Guardia, J. G., Ryan, R. M., Couchman, C. E., \& Deci, E. L. (2000). Within-person variation in security of attachment: A self-determination theory perspective on attachment, need fulfillment, and well-being. Journal of Personality and Social Psychology, 79, 367-384.

Laghi, F., D’Alessio, M., Pallini, S., \& Baiocco, R. (2009). Attachment representations and time perspective in adolescence. Social Indicators Research, 90, 181-194.

Lalwani, A. K., \& Shavitt, S. (2009). The "me" I claim to be: Cultural self-construal elicits self-presentational goal pursuit. Journal of Personality and Social Psychology, 97, 88-102.

Lamborn, S. D., \& Groh, K. (2009). A four-part model of autonomy during emerging adulthood: Associations with adjustment. International Journal of Behavioral Development, 33, 393-401.

Larson, R. W. (2000). Toward a psychology of positive youth development. American Psychologist, 55, 170-183.

Lee, C. T., Beckert, T. E., \& Goodrich, T. R. (2010). The relationship between individualistic, collectivistic, and transitional cultural value orientations and adolescents' autonomy and identity status. Journal of Youth and Adolescence, 39, 882-893.
1489

1490

1491

1492

1493

1494

1495

1496

1497

1498

1499

1500

1501

1502

1503

1504

1505

1506

1507

1508

1509

1510

1511

1512

1513

1514

1515

1516

1517

1518

1519

1520

1521

1522

1523

1524

1525

1526

1527

1528

1529

1530

1531

1532

1533

1534

1535

1536

1537

1538

1539

1540

1541

1542

1543

1544

1545

1546

1547

1548

1549

1550

1551

1552

1553 
Levine, J. B., Green, C. J., \& Millon, T. (1986). The separationindividuation test of adolescence. Journal of Personality Assessment, 50, 123-137.

Little, R. (1988). A test of missing completely at random for multivariate data with missing values. Journal of the American Statistical Association, 83, 1198-1202.

Lopez, F. G., Campbell, V. L., \& Watkins, C. E. (1988). Family structure, psychological separation, and college adjustment: A canonical analysis and cross-validation. Journal of Counseling Psychology, 35, 402-409.

Lorenzo-Seva, U., \& ten Berge, J. M. F. (2006). Tucker's congruence coefficient as a meaningful index of factor similarity. Methodology: European Journal of Research Methods for the Behavioral and Social Sciences, 2, 57-64.

Luyckx, K., Goossens, L., Soenens, B., \& Beyers, W. (2006). Unpacking commitment and exploration: Preliminary validation of an integrative model of late adolescent identity formation. Journal of Adolescence, 29, 361-378.

Markus, H. R., \& Kitayama, S. (1991). Culture and the self: Implications for cognition, emotion, and motivation. Psychological Review, 98, 224-253.

Marsh, H. W. (1994). Sport motivation orientations: Beware of jingle-jangle fallacies. Journal of Sport \& Exercise Psychology, $16,365-380$.

Mayseless, O., Wiseman, H., \& Hai, I. (1998). Adolescents' relationships with father, mother, and same-gender friend. Journal of Adolescent Research, 13, 101-123.

McCrae, R. R., Zonderman, A. B., Bond, M. H., Costa, P. T., \& Paunonen, S. V. (1996). Evaluating replicability of factors in the revised NEO personality inventory: Confirmatory factor analysis versus procrustes rotation. Journal of Personality and Social Psychology, 70, 552-566.

Mikulincer, M., \& Shaver, P. R. (2007a). Reflections on security dynamics: Core constructs, psychological mechanisms, relational contexts, and the need for an integrative theory. Psychological Inquiry, 18, 197-209.

Mikulincer, M., \& Shaver, P. R. (2007b). Attachment in adulthood: structure, dynamics and change. New York: Guilford Press.

Mikulincer, M., Shaver, P. R., Bar-On, N., \& Ein-Dor, T. (2010). The pushes and pulls of close relationships: Attachment insecurities and relational ambivalence. Journal of Personality and Social Psychology, 98, 450-468.

Qin, L. L., Pomerantz, E. M., \& Wang, Q. (2009). Are gains in decision-making autonomy during early adolescence beneficial for emotional functioning? The case of the United States and China. Child Development, 80, 1705-1721.

Radloff, S. L. (1977). The CES-D scale: A self-report depression scale for research in the general population. Applied Psychological Measurement, 1, 385-401.

Rice, K. G. (1992). Separation-individuation and adjustment to college: A longitudinal study. Journal of Counseling Psychology, 39, 203-213.

Robins, C. J., Ladd, J., Welkowitz, J., Blaney, P. H., Diaz, R., \& Kutcher, G. (1994). The Personal Style Inventory: Preliminary validation studies of new measures of sociotropy and autonomy. Journal of Psychopathology and Behavioral Assessment, 16, 277-300.

Rummel, R. J. (1970). Applied factor analysis. Evanston, IL: Northwestern University.

Ryan, R. M., \& Deci, E. L. (2000). Self-determination theory and the facilitation of intrinsic motivation, social development, and wellbeing. American Psychologist, 55, 68-78.

Ryan, R. M., \& Deci, E. L. (2006). Self-regulation and the problem of human autonomy: Does psychology need choice, self-determination, and will? Journal of Personality, 74, 1557-1585.

Ryan, R. M., Deci, E. L., Grolnick, W. S., \& LaGuardia, J. G. (2006). The significance of autonomy and autonomy support in psychological development and psychopathology. In D. Cicchetti \& D. Cohen (Eds.), Developmental psychopathology: Vol. 1: Theory and methods (2nd ed., pp. 795-849). New York: Wiley.

Ryan, R. M., \& Frederick, C. (1997). On energy, personality, and health: Subjective vitality as a dynamic reflection of well-being. Journal of Personality, 65, 529-565.

Ryan, R. M., La Guardia, J. G., Solky-Butzel, J., Chirkov, V., \& Kim, Y. M. (2005). On the interpersonal regulation of emotions: Emotional reliance across gender, relationships, and cultures. Personal Relationships, 12, 145-163.

Ryan, R. M., \& Lynch, J. H. (1989). Emotional autonomy versus detachment: Revisiting the vicissitudes of adolescence and young adulthood. Child Development, 60, 340-356.

Saunders, J. B., Aasland, O. G., Babor, T. F., Delafuente, J. R., \& Grant, M. (1993). Development of the alcohol use disorders identification test (AUDIT): WHO collaborative project on early detection of persons with harmful alcohol consumption-II. Addiction, 88, 791-804.

Schafer, J. L. (1997). Analysis of incomplete multivariate data. London: Chapman \& Hall.

Schönemann, P. H. (1966). A generalized solution of the orthogonal Procrustes problem. Psychometrika, 31, 1-10.

Sheldon, K. M., Houser-Marko, L., \& Kasser, T. (2006). Does autonomy increase with age? Comparing the goal motivations of college students and their parents. Journal of Research in Personality, 40, 168-178.

Sheldon, K. M., Ryan, R., \& Reis, H. T. (1996). What makes for a good day? Competence and autonomy in the day and in the person. Personality and Social Psychology Bulletin, 22, $1270-1279$.

Shen, L. J., \& Dillard, J. P. (2005). Psychometric properties of the Hong Psychological Reactance Scale. Journal of Personality Assessment, 85, 74-81.

Silverberg, S. B., \& Gondoli, D. M. (1996). Autonomy in adolescence: A contextualized perspective. In G. R. Adams, R. Montemayor, \& T. P. Gullotta (Eds.), Psychosocial development during adolescence (pp. 12-61). Thousand Oaks, CA: Sage.

Smetana, J. G. (2000). Middle-class African American adolescents' and parents' conceptions of parental authority and parenting practices: A longitudinal investigation. Child Development, 71, $1672-1686$.

Smetana, J. G., Campione-Barr, N., \& Daddis, C. (2004). Longitudinal development of family decision making: Defining healthy behavioral autonomy for middle-class African American adolescents. Child Development, 75, 1418-1434.

Soenens, B., \& Beyers, W. (2012). The cross-cultural significance of control and autonomy in parent-adolescent relationships. Journal of Adolescence, 35, 243-248.

Soenens, B., \& Vansteenkiste, M. (2005). Antecedents and outcomes of self-determination in 3 life domains: The role of parents' and teachers' autonomy support. Journal of Youth and Adolescence, 34, 589-604.

Soenens, B., Vansteenkiste, M., Lens, W., Luyckx, K., Goossens, L., Beyers, W., et al. (2007). Conceptualizing parental autonomy support: Adolescent perceptions of promotion of independence versus promotion of volitional functioning. Developmental Psychology, 43, 633-646.

Steinberg, L. (2002). Adolescence (6th ed.). Boston, MA: McGrawHill.

Thorndike, E. L. (1904). An introduction to the theory of mental and social measurements. New York: Teachers College, Columbia University.

Vallerand, R. J. (1997). Toward a hierarchical model of intrinsic and extrinsic motivation. Advances in Experimental Social Psychology, 29, 271-360.

\begin{tabular}{|c|c|c|c|c|}
\hline & Journal : Large 10964 & Dispatch : & 26-10-2012 & Pages: 21 \\
\hline & $\begin{array}{l}\text { Article No. : } \mathbf{9 8 4 7} \\
\text { MS Code : } \quad \text { JOYO-2968 }\end{array}$ & $\begin{array}{l}\square \mathrm{LE} \\
\boldsymbol{\sim}_{\mathrm{CP}} \\
\end{array}$ & & $\begin{array}{ll}\square & \text { TYPESET } \\
\boldsymbol{V} & \text { DISK } \\
\end{array}$ \\
\hline
\end{tabular}


Vallerand, R. J. (2000). Deci and Ryan's self-determination theory: A view from the hierarchical model of intrinsic and extrinsic motivation. Psychological Inquiry, 11, 312-318.

Van Petegem, S., Beyers, W., Vansteenkiste, M., \& Soenens, B. (2012). On the association between adolescent autonomy and psychosocial functioning: Examining decisional independence from a Self-Determination Theory perspective. Developmental Psychology, 48, 76-88.

Vansteenkiste, M., Soenens, B., Van Petegem, S., Wuyts, D., \& Duriez, B. (2012). Longitudinal associations between adolescent perceived style of parental prohibition and oppositional defiance and internalization. Manuscript submitted for publication.

Vansteenkiste, M., Zhou, M. M., Lens, W., \& Soenens, B. (2005). Experiences of autonomy and control among Chinese learners: Vitalizing or immobilizing? Journal of Educational Psychology, 97, 468-483.

Weinmann, L. L. (1992). Patterns of change in middle adolescent adjustment: The role of relationships with parents and peers. Dissertation Abstracts International, 53, 2565B-2566B.

Youniss, J., \& Smollar, J. (1985). Adolescent relations with mothers, fathers, and friends. Chicago: University of Chicago Press.

Zimmer-Gembeck, M. J., \& Collins, W. A. (2003). Autonomy development during adolescence. In G. R. Adams \& M. D. Berzonsky (Eds.), Blackwell handbook of adolescence (pp. 175-204). Oxford, England: Blackwell.

Zwick, W. R., \& Velicer, W. F. (1982). Factors influencing four rules for determining the number of components to retain. Multivariate Behavioral Research, 17, 253-269.

\section{Author Biographies}

Stijn Van Petegem is a PhD student at the Department of Developmental, Personality and Social Psychology at Ghent University, Belgium. He received his master in clinical psychology in 2008. His major research interests include autonomy, self-determination theory, psychological reactance, attachment and identity development.

Maarten Vansteenkiste is Professor at the Department of Developmental, Personality and Social Psychology at Ghent University, Belgium. He received his Ph.D. in 2005 from the Catholic University of Leuven. His major research interests include the study of motivation and autonomy in diverse life domains, including adolescence and parenting.

Wim Beyers is Professor at the Department of Developmental, Personality and Social Psychology at Ghent University, Belgium. He received his Ph.D. in 2001 from the Catholic University of Leuven. His major research interests include the development of autonomy, identity and sexuality in adolescence.
1717

1719

1720

1721

1722

1723

1724

1725

1726

1727

1728

1729

1730

1731

1732

1733

1734

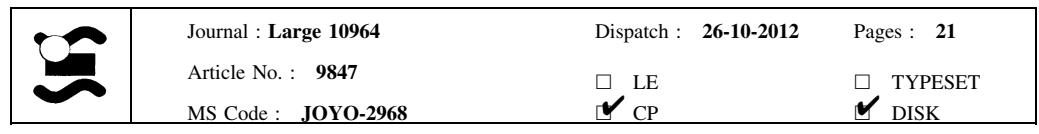

